\title{
Is there an efficacy-effectiveness gap between randomized controlled trials and real-world studies in colorectal cancer: a systematic review and meta-analysis
}

\author{
Xiao Zhang, Shihui Fu, Rui Meng, Yu Ren, Ye Shang, Lei Tian \\ School of International Pharmaceutical Business, China Pharmaceutical University, Nanjing, China \\ Contributions: (I) Conception and design: L Tian, X Zhang; (II) Administrative support: L Tian; (III) Provision of study materials or patients: L Tian, \\ X Zhang; (IV) Collection and assembly of data: X Zhang, S Fu, R Meng, Y Ren, Y Shang; (V) Data analysis and interpretation: X Zhang, R Meng; (VI) \\ Manuscript writing: All authors; (VII) Final approval of manuscript: All authors. \\ Correspondence to: Lei Tian. School of International Pharmaceutical Business, China Pharmaceutical University, No. 639 Longmian Avenue, Jiangning \\ District, Nanjing, China. Email: cputianlei@163.com.
}

\begin{abstract}
Background: To investigate whether patients with colorectal cancer (CRC) enrolled in randomized controlled trials (RCTs) and real-world studies (RWS) differ in terms of baseline characteristics, leading to an efficacy-effectiveness gap.
\end{abstract}

Methods: A systematic literature reviews was conducted to identify RCTs and RWS with CRC, treated with bevacizumab (BEV), cetuximab (CET) or oxaliplatin combined with capecitabine (XELOX). Using random-effects meta-analyses compared the baseline characteristics and treatment effects of RCTs and RWS, overall and by drug. Correlation between treatment effects and baseline characteristics and study types were estimated using meta-regression analyses.

Results: Two hundred and fifty-three studies were included. Compared with patients enrolled in RWS, the proportion of male patients in RCTs was 0.032 higher $(\mathrm{P}=0.004)$, the proportion of patients with Eastern Cooperative Oncology Group (ECOG) performance $\geq 2$ was 0.085 less $(\mathrm{P}<0.001)$. No significant differences in treatment effects [progression-free survival (PFS), overall survival (OS), objective response rate (ORR), disease control rate (DCR)] were found by overall analysis. But the OS of patients in RCTs was 4.184 higher $(\mathrm{P}=0.023)$ in the CET group. Meta-regression results showed that OS difference in the CET group was related to the difference in treatment lines, not related to other baseline characteristics and study types.

Conclusions: No efficacy-effectiveness gap was found in CRC between RCTs and RWS. CRC treatment effects Between RCTs and RWS had high consistency.

Keywords: Efficacy-effectiveness gap; randomized controlled trials (RCTs); real-world studies (RWS); colorectal cancer (CRC)

Submitted Jun 11, 2020. Accepted for publication Sep 26, 2020.

doi: $10.21037 /$ tcr-20-2303

View this article at: http://dx.doi.org/10.21037/tcr-20-2303

\section{Introduction}

In the process of developing clinical diagnosis and treatment guidelines and healthcare policy, it is essential to obtain valid clinical trial evidence, in which randomized controlled trials (RCTs) are recognized as the gold standard for evaluating interventions (1). In most countries, such as the United Kingdom, Canada, and South Korea, the development of health decision-making and clinical practice guidelines are based on research-based RCTs (2). With the increasingly complicated situation and high cost of cancer treatment, the conducting clinical trials in cancer are facing more challenges. People have begun to realize that RCTs do not match the real-world environment and lack external validity, due to moderately and highly standardized trial 
Table 1 Search strategy

\begin{tabular}{ll}
\hline No. & Search strategy \\
\hline 1 & $\begin{array}{l}\text { (colorectal cancer or CRC or Colorectal carcinoma } \\
\text { or Colorectal neoplasms).ti,ab,ot,hw,rn. }\end{array}$ \\
2 & (Cetuxim* or Erbitux).ti,ab,ot,hw,rn. \\
3 & (Bevacizum\$b or CAPOX-B).ti,ab,ot,hw,rn. \\
4 & (Oxaliplatin or L-OHP or OXA).ti,ab,ot,hw,rn. \\
5 & (capecitabine or Xeloda or ECX).ti,ab,ot,hw,rn. \\
6 & 4 and 5 \\
7 & XELOX or CapeOX.ti,ab,ot,hw,rn. \\
8 & Or/6-7 \\
9 & Or/2,3,8 \\
10 & 1 and 9 \\
11 & limit 10 to yr=“2009-current" \\
\hline
\end{tabular}

designs, strict patient inclusion and exclusion criteria, and short follow-up time (3). Unlike RCTs, real-world studies (RWS) are a type of research that reflects the actual clinical diagnosis and treatment process, based on the real-world data. Principles of its research design are mainly nonrandomization, non-intervention, and openness, which are closer to the actual clinical treatment environment and have higher external validity. RWS have received an increasing amount of attention, since the United States Congress passed the 21st Century Cures Act in 2016, which made it clear that the FDA could use real-world data as evidence of approval for post-marketing research and new indications for medical devices and drugs, where appropriate. In 2018, the FDA announced Real-World Evidence Program, which presents a detailed standard for evaluating the quality of real-world evidence. Recently, the FDA approved a new indication for Pfizer's Ibrance based on the real-world data, which is the first drug indication approved by the FDA based on real-world data. RWS immediately ignited the hot topic $(4,5)$.

There has been much controversy about the application and differences in results between RCTs and RWS. A study by Jaksa et al. (6) showed that RWS may amplify the positive effects of interventions and allow health policymakers to make favorable decisions. A study by Naudet et al. (7) showed that RCTs are more efficient than RWS in the study of treatment for major depression. Some studies (8-12) have compared the baseline characteristics and treatment effects of patients in RCTs and RWS and showed that RCTs tend to include patients with better prognostic factors and high treatment effects. They also proposed the concept of the efficiency-effectiveness gap to describe the gap between treatment effects observed in RCTs and those observed in RWS. However, other studies (13-18) have shown that most RCTs in the same disease and treatment methods have very similar results to RWS. As the design and reporting quality of RWS improve, respectively, the consistency with the results of RCTs becomes higher.

Although there is much debate about the differences between RCTs and RWS, comparative studies for colorectal cancer (CRC) are still lacking. no valid evidence is available to indicate the difference between RCTs and RWS in CRC. Based on previous studies, we performed a meta-analysis to investigate whether patients with CRC enrolled in RCTs and RWS differ in terms of baseline characteristics, leading efficacy-effectiveness gap. Oxaliplatin combined with capecitabine (XELOX), and targeted drugs [e.g., cetuximab (CET), bevacizumab (BEV)] combined with chemotherapy should be used as effective first- and second-line treatments for chemotherapy-resistant patients with metastatic CRC according to NCCN Clinical practice guidelines in oncology (version 1.2017) (19) and The Chinese Diagnosis and Treatment Specification of Colorectal Cancer (2017 edition) (20). Therefore, this study selected XELOX, CET monotherapy or combined chemotherapy, BEV monotherapy or combined chemotherapy as the therapeutic regimens.

We present the following article in accordance with the PRISMA reporting checklist (available at http://dx.doi. org/10.21037/tcr-20-2303).

\section{Methods}

\section{Literature search strategy}

We searched Medline and Embase to find relevant articles published from 20 September 2009 to 20 September 2019 in English using the main search terms "bevacizumab", "cetuximab", "XELOX" and "colorectal cancer". Considering the incomplete development of real-world research methods, the database search was limited to last 10 years of research. In addition, references for secondary research were manually retrieved to supplement the original research literature. Specific search strategies show in Table 1.

\section{Study selection}

Titles and abstracts of all retrieved literature were imported into the NoteExpress V3.2.0. The repeat literature was 
removed. Two reviewers (XZ and SF) independently performed the study selection, including screening titles and abstracts, and evaluating full-text eligibility of potentially eligible studies. Discussion or negotiation with a third party was implemented if there were divergences. If necessary, we contacted the original authors by email or phone to obtain unidentified information.

Included studies need to meet the following criteria: (I) studies that enrolled patients with CRC treated with BEV, CET or XELOX; (II) studies that reported on at least one of the following clinical outcomes: (i) primary outcomes: progression-free survival (PFS), overall survival (OS); (ii) secondary outcomes: response rate (RR) including disease control rate (DCR), objective response rate (ORR), complete response rate $(\mathrm{CR})$, partial response rate $(\mathrm{PR})$, and stable disease (SD) based on the measurement of cancer antigen 125 levels confirmed by radiological examination results or by combined Gynecologic Cancer InterGroup criteria.

Studies not meeting the inclusion criteria were excluded. Other exclusion criteria were: (I) studies in which BEV, CET or XELOX was used as neoadjuvant treatments; (II) studies with a sample size of less than 30; (III) non-English studies.

\section{Data extraction}

Data from each included paper were extracted into a standardized spreadsheet developed for this project by two reviewers independently with adjudication by a third reviewer: study characteristics (e.g., title, author, publication year, study design, country, study horizon, follow-up time, trial name, and registration number); treatments (e.g., drug, dose, frequency, and cycle); patient characteristics (e.g., sample size, age, gender, Eastern Cooperative Oncology Group (ECOG), treatment line, tumor location, and transfer); treatment effects (e.g., PFS, OS, RR, DCR, ORR, CR, PR, and SD). We extracted frequency number and percentages. All patients included in the study were fully enrolled in the primary studies, and no witching over treatment or treatment discontinuation.

\section{Data synthesis and statistical analysis}

Data on patient baseline characteristics (age, proportions of male, proportion of patients with ECOG $\geq 2$, proportion of patients with second-line and above second-line treatment) and treatment effects (PFS, OS, ORR, DCR) were finally analyzed. The ORR $=\mathrm{CR}+\mathrm{PR}$ and $\mathrm{DCR}=\mathrm{ORR}+\mathrm{SD}$ were used to process the tumor response results. The methods described by Wan et al. (21) were used to convert the mean and range of continuous variables such as age, PFS, and OS into mean and standard deviation, whereas the other variables were presented as ratios. We first combine the baseline characteristics and treatment effects of CRC patients in RCTs and RWS using random-effect metaanalyses, and subsequently to compare the difference of the combined results.

We used meta-regression analyses to assess the heterogeneity by including the baseline characteristics as covariates, the study design as a dichotomous covariate, and treatment effects as dependent variables. We used restricted maximum-likelihood estimation to assess between-study variance (tau-squared) and applied the Knapp-Hartung adjustment (22).

Considering the follow-up time, treatment cycle and duration would have a major impact on the treatment effects, a comparative analysis of follow up time, treatment cycle and duration between RCT and RWS was added. All analyses were done in the Stata SE15.

\section{Results}

\section{Characteristics of included studies}

We identified 6,147 records through database searching, and 2 potentially eligible studies through other sources. After duplicate checking and title and abstract screening, 369 full-text articles assessed for eligibility. Finally, 369 fulltext articles assessed for eligibility. Finally, 201 articles were eventually included: 117 RCTs including 94 phase II clinical trials, 6 phase III clinical trials, and 17 unknown phase clinical trials; 84 RWS including 36 case series, 13 registry, 20 cohort, and 15 unknown category of studies. There were 102 studies on BEV treatment, 54 studies on CET treatment, and 45 studies on XELOX treatment. A total of 37,479 patients were included, with 13,889 patients in RCTs and 23,590 patients in RWS. The process and results of article selection show in Figure 1. The main characteristics of all studies show in Tables 2,3.

\section{Comparison of patient characteristics}

Compared with patients enrolled in RWS, the proportion of male patients in RCTs was 0.032 higher $(0.613,0.598$ to 0.628 vs. $0.581,0.565$ to $0.597 ; \mathrm{P}=0.004)$, the proportion of patients with ECOG $\geq 2$ was 0.085 less $(0.005,0.003$ to 0.006 vs. $0.090,0.078$ to $0.103 ; \mathrm{P}<0.001)$. No significant 


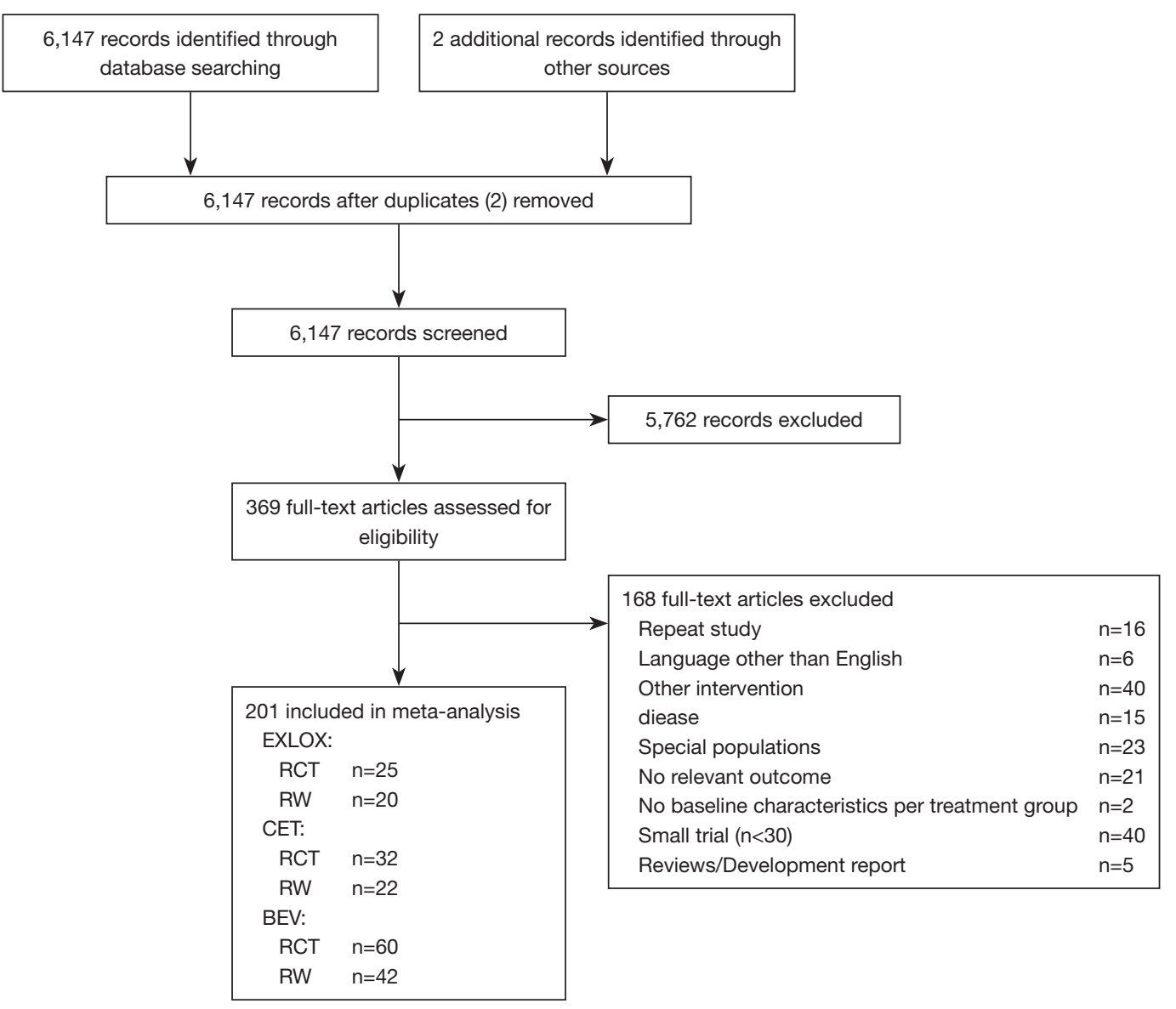

Figure 1 Flow chart. RCT, randomized controlled trial; RWS, real-world studies; BEV, bevacizumab; CET, cetuximab; XELOX, oxaliplatin combined with capecitabine.

differences in age and treatment line were found (Figure 2).

Subgroup analysis by drug showed that differences generally were in the same direction for the three drugs: the proportion of male patients in RCTs was 0.060 higher than those in RWS $(0.622,0.580$ to 0.664 vs. $0.562,0.524$ to $0.600 ; \mathrm{P}=0.038)$ in the XELOX group; the proportion of patients with ECOG $\geq 2$ in RCTs was 0.075 less than those in RWS $(0.006,0.003$ to 0.008 vs. $0.081,0.065$ to $0.98 ; \mathrm{P}<0.001)$ in the $\mathrm{BEV}$ group, and similar results was also found in the CET group [0.175 less than those in RWS (0.006, 0.003 to 0.009 vs. $0.181,0.118$ to $0.245 ; \mathrm{P}<0.001)$ ]. Furthermore, patients in RCTs were 1.304 years older than those in RWS $(59.205,58.520$ to 59.890 vs. $57.901,56.839$ to $58.963 ; \mathrm{P}=0.043$ ) in the $\mathrm{BEV}$ group; the proportion of patients with second-line and above second-line treatment in RCTs was 0.350 lower than those in RWS $(0.281,0.136$ to 0.427 vs. $0.631,0.403$ to $0860 ; \mathrm{P}=0.012$ ) in the CET group (Figure 2). More detailed results show in Table S1 and Figures S1-S8.

\section{Comparison of treatment effects}

\section{Primary outcomes}

No significant differences were found in OS and PFS between RCTs and RWS by overall analysis. The results of subgroup analysis by drug were mostly consistent with the overall analysis, no significant differences were found in the BEV group and XELOX group, but patients in the CET group of RCTs had an OS of 4.184 months higher than that of patients in the CET group of RWS (17.432 months, 15.118 to 19.745 vs. $13.248,11.281$ to $15.215 ; \mathrm{P}=0.023$ ) (Figure 3). 
Table 2 Baseline characteristics of RCTs

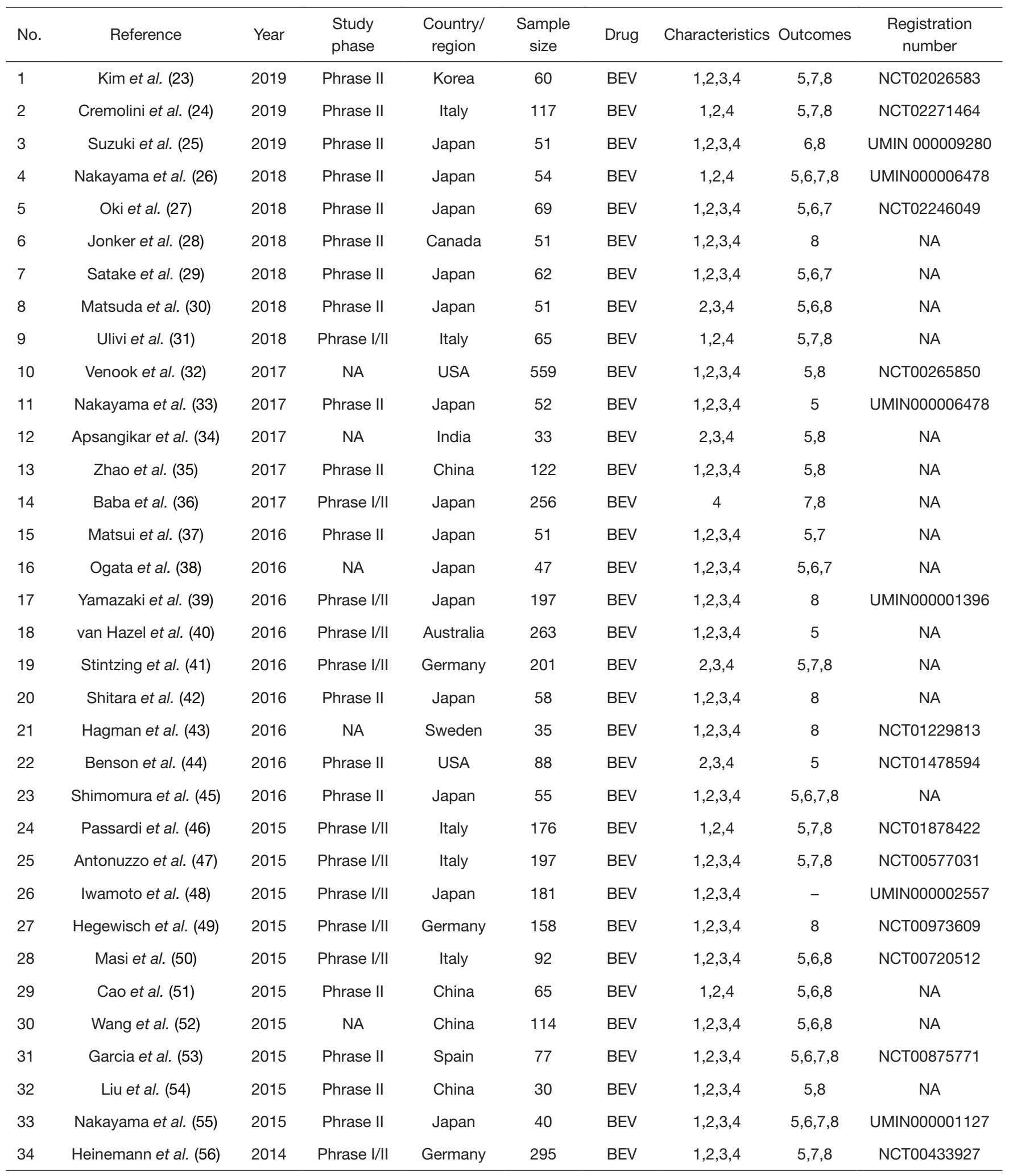

Table 2 (continued) 
Table 2 (continued)

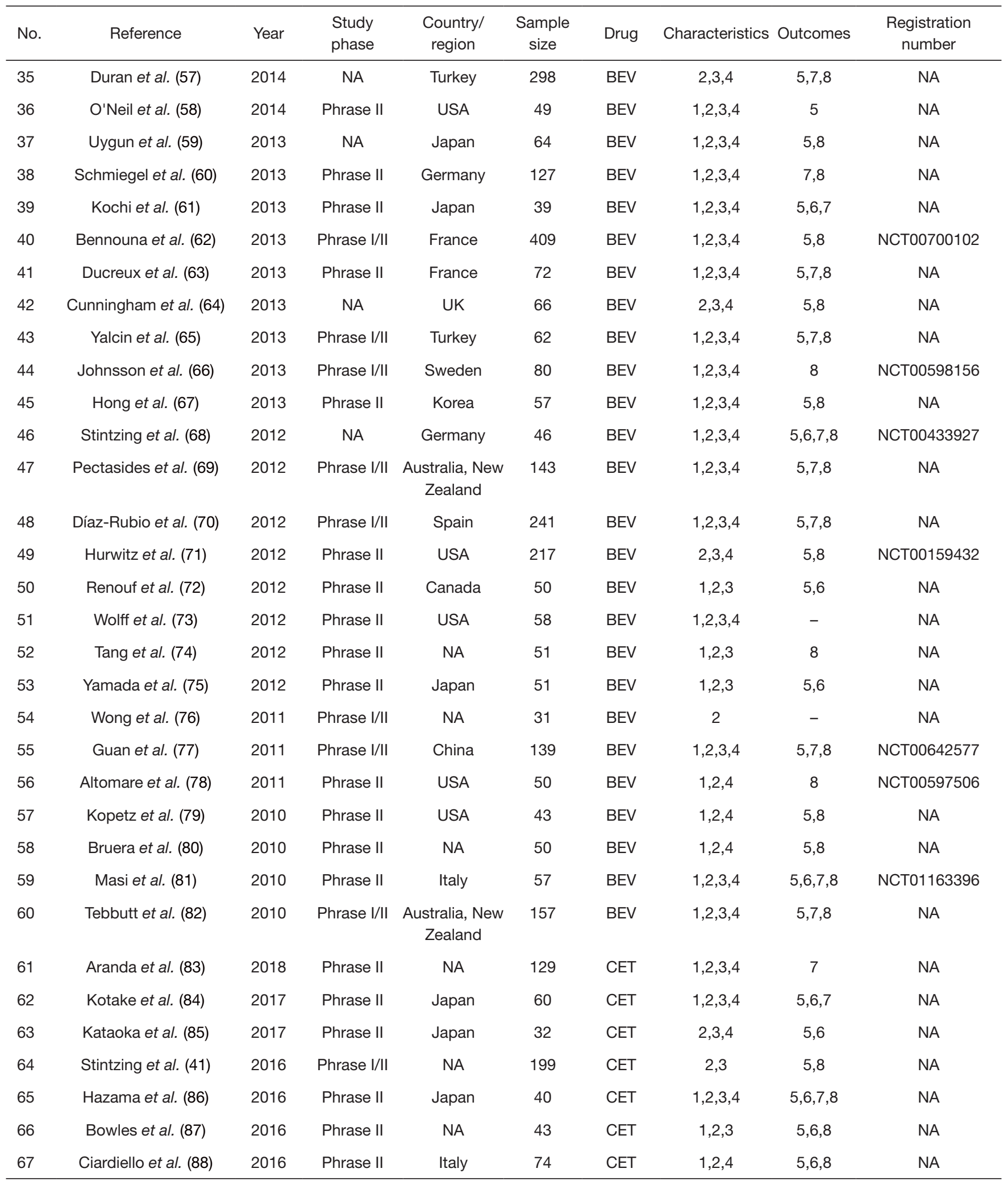

Table 2 (continued) 
Table 2 (continued)

\begin{tabular}{|c|c|c|c|c|c|c|c|c|c|}
\hline No. & Reference & Year & $\begin{array}{l}\text { Study } \\
\text { phase }\end{array}$ & $\begin{array}{l}\text { Country/ } \\
\text { region }\end{array}$ & $\begin{array}{l}\text { Sample } \\
\text { size }\end{array}$ & Drug & Characteristics & Outcomes & $\begin{array}{l}\text { Registration } \\
\text { number }\end{array}$ \\
\hline 68 & Eng et al. (89) & 2016 & Phrase II & NA & 60 & CET & $1,2,3,4$ & $5,6,7,8$ & NA \\
\hline 70 & Sclafani et al. (91) & 2015 & Phrase I/II & UK & 119 & CET & $2,3,4$ & 5,6 & NA \\
\hline 71 & Do et al. (92) & 2015 & Phrase II & USA & 30 & CET & $1,2,4$ & 5,7 & NA \\
\hline 73 & Fernandez et al. (94) & 2014 & Phrase II & Spain & 99 & CET & $1,2,3,4$ & $5,6,7,8$ & NA \\
\hline 74 & Heinemann et al. (56) & 2014 & Phrase I/II & Germany & 297 & CET & $1,2,3,4$ & $5,6,7,8$ & NA \\
\hline 75 & Iwamoto et al. (95) & 2014 & Phrase II & Japan & 60 & CET & $1,2,3,4$ & $5,6,8$ & NA \\
\hline 79 & Brodowicz et al. (99) & 2013 & NA & NA & 75 & CET & $1,2,4$ & $5,6,7,8$ & NA \\
\hline 80 & Hong et al. (100) & 2013 & NA & NA & 40 & CET & $1,2,3,4$ & $5,6,8$ & NA \\
\hline 81 & Assenat et al. (101) & 2011 & Phrase II & France & 42 & CET & $1,2,3,4$ & $5,6,7$ & NA \\
\hline 82 & Kullmann et al. (102) & 2011 & Phrase II & NA & 62 & CET & $1,2,4$ & $5,6,7,8$ & NA \\
\hline 83 & Lim et al. (103) & 2011 & Phrase II & $\begin{array}{c}\text { Asian, } \\
\text { Australia }\end{array}$ & 123 & CET & $1,2,4$ & $5,6,8$ & NA \\
\hline 84 & Van et al. (104) & 2011 & Phrase I/II & Europe & 599 & CET & $1,2,3,4$ & $5,6,7,8$ & NA \\
\hline 85 & Moosmann et al. (105) & 2011 & Phrase II & Germany & 89 & CET & $1,2,4$ & 5,6 & NA \\
\hline 90 & Shitara et al. (109) & 2012 & Phrase II & Japan & 30 & CET & $1,2,3,4$ & 5,6 & NA \\
\hline 91 & Tveit et al. (110) & 2012 & Phrase I/II & Europe & 194 & CET & $1,2,3,4$ & $5,7,8$ & NA \\
\hline 92 & Mrabti et al. (111) & 2009 & Phrase I/II & Morocco & 32 & CET & $1,2,4$ & 5 & NA \\
\hline 93 & Mizushima et al. (112) & 2019 & Phrase II & Japan & 107 & XELOX & $1,2,3$ & - & NA \\
\hline 94 & Yoshimatsu et al. (113) & 2019 & Phrase II & Japan & 57 & XELOX & 1,2 & - & ID:000005427 \\
\hline 95 & Nishimura et al. (114) & 2018 & Phrase II & Japan & 42 & XELOX & $1,2,3$ & - & NA \\
\hline 96 & Larsen et al. (115) & 2017 & Phrase II & NA & 52 & XELOX & $1,2,3$ & - & NCT00964457 \\
\hline 97 & Danno et al. (116) & 2017 & Phrase II & Japan & 190 & XELOX & $1,2,3$ & 5 & ID:000006742 \\
\hline 98 & Azria et al. (117) & 2017 & NA & France & 291 & XELOX & 1,2 & - & NA \\
\hline 99 & Liu et al. (118) & 2016 & Phrase II & China & 47 & XELOX & 1,2 & 5,6 & NCT02415829 \\
\hline 100 & Pilanci et al. (119) & 2016 & Phrase II & Turkey & 30 & XELOX & $1,2,3$ & 5,8 & NO:44140529 \\
\hline 101 & Feng et al. (120) & 2016 & Phrase III & China & 224 & XELOX & 1,2 & - & NCT00714077 \\
\hline
\end{tabular}

Table 2 (continued) 
Table 2 (continued)

\begin{tabular}{|c|c|c|c|c|c|c|c|c|c|}
\hline No. & Reference & Year & $\begin{array}{l}\text { Study } \\
\text { phase }\end{array}$ & $\begin{array}{l}\text { Country/ } \\
\text { region }\end{array}$ & $\begin{array}{c}\text { Sample } \\
\text { size }\end{array}$ & Drug & Characteristics & Outcomes & $\begin{array}{l}\text { Registration } \\
\text { number }\end{array}$ \\
\hline 102 & Sclafani et al. (121) & 2016 & Phrase II & UK & 50 & XELOX & $1,2,3$ & - & NCT00958737 \\
\hline 104 & Wong et al. (123) & 2015 & Phrase II & USA & 52 & XELOX & $1,2,3$ & - & NA \\
\hline 105 & Kim et al. (124) & 2014 & Phrase III & Korea & 172 & XELOX & 2,3 & - & NCT00677443 \\
\hline 107 & Gérard et al. (125) & 2012 & NA & France & 299 & XELOX & - & - & NA \\
\hline 108 & Salazar et al. (126) & 2012 & Phrase II & Spain & 45 & XELOX & $1,2,3$ & 5,6 & NA \\
\hline 109 & Arbea et al. (127) & 2012 & Phrase II & Spain & 100 & XELOX & 1,2 & - & NA \\
\hline 113 & Waddell et al. (131) & 2011 & Phrase II & UK & 45 & XELOX & $1,2,3$ & $5,6,8$ & NA \\
\hline 114 & Baraniskin et al. (132) & 2011 & Phrase III & Germany & 190 & XELOX & 2,4 & $5,7,8$ & NA \\
\hline 115 & Cassidy et al. (133) & 2011 & Phrase III & UK & 317 & XELOX & $1,2,3,4$ & 8 & N016966 \\
\hline 116 & Li et al. (134) & 2010 & Phrase II & China & 124 & XELOX & $1,2,3,4$ & $5,7,8$ & NA \\
\hline 117 & Qvortrup et al. (135) & 2010 & Phrase II & Denmark & 70 & XELOX & $1,2,3,4$ & 8 & NA \\
\hline
\end{tabular}

Age =1; gender =2; ECOG =3; treat-line =4; ORR =5; DCR =6; PFS =7; OS =8. UK, United Kingdom; USA, the United States of America; NA, not available; BEV, bevacizumab; CET, cetuximab; XELOX, oxaliplatin combined with capecitabine; ECOG, Eastern Cooperative Oncology Group.

Table 3 Baseline characteristics of RWS

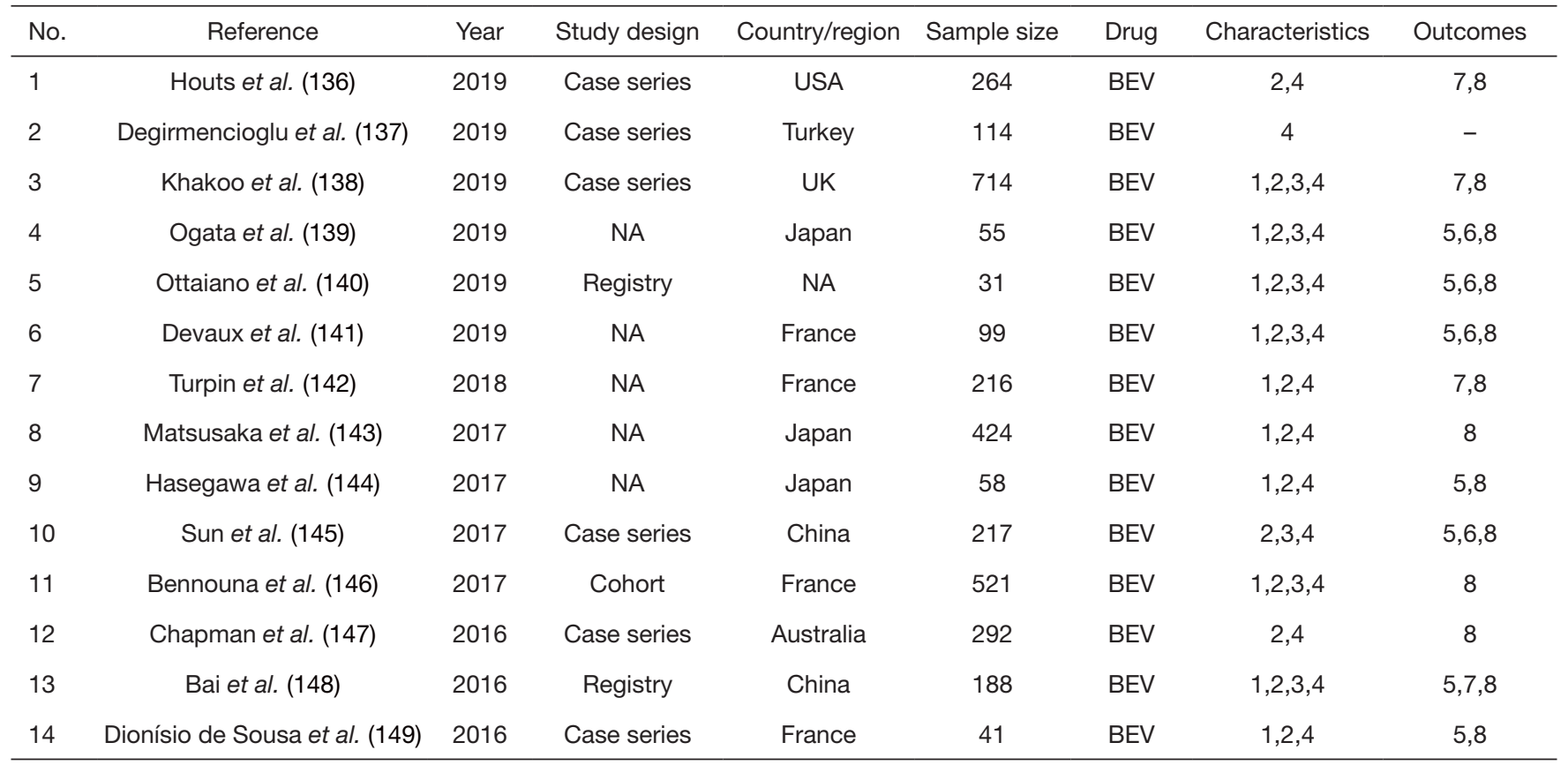

Table 3 (continued) 
Table 3 (continued)

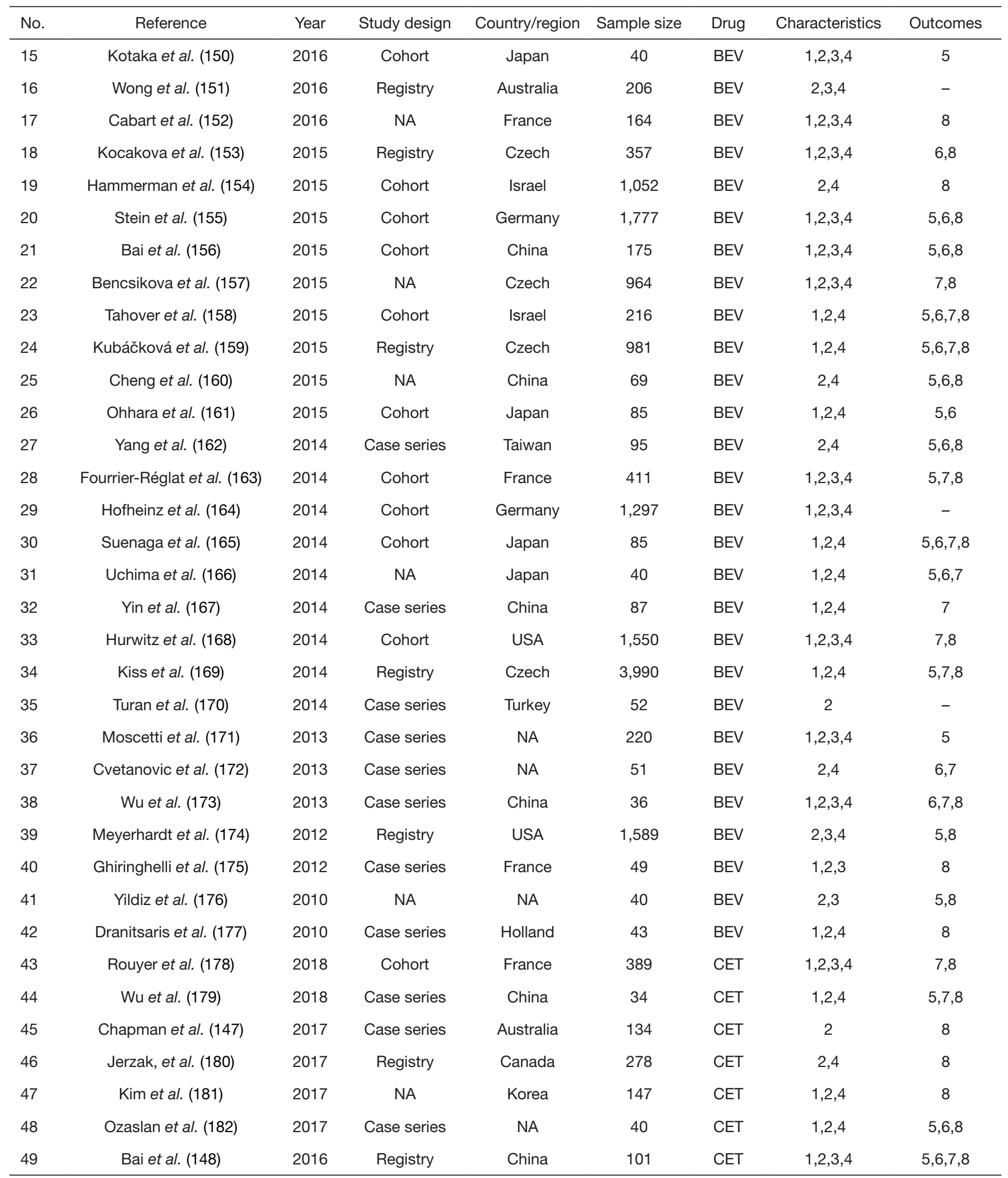

Table 3 (continued) 
Table 3 (continued)

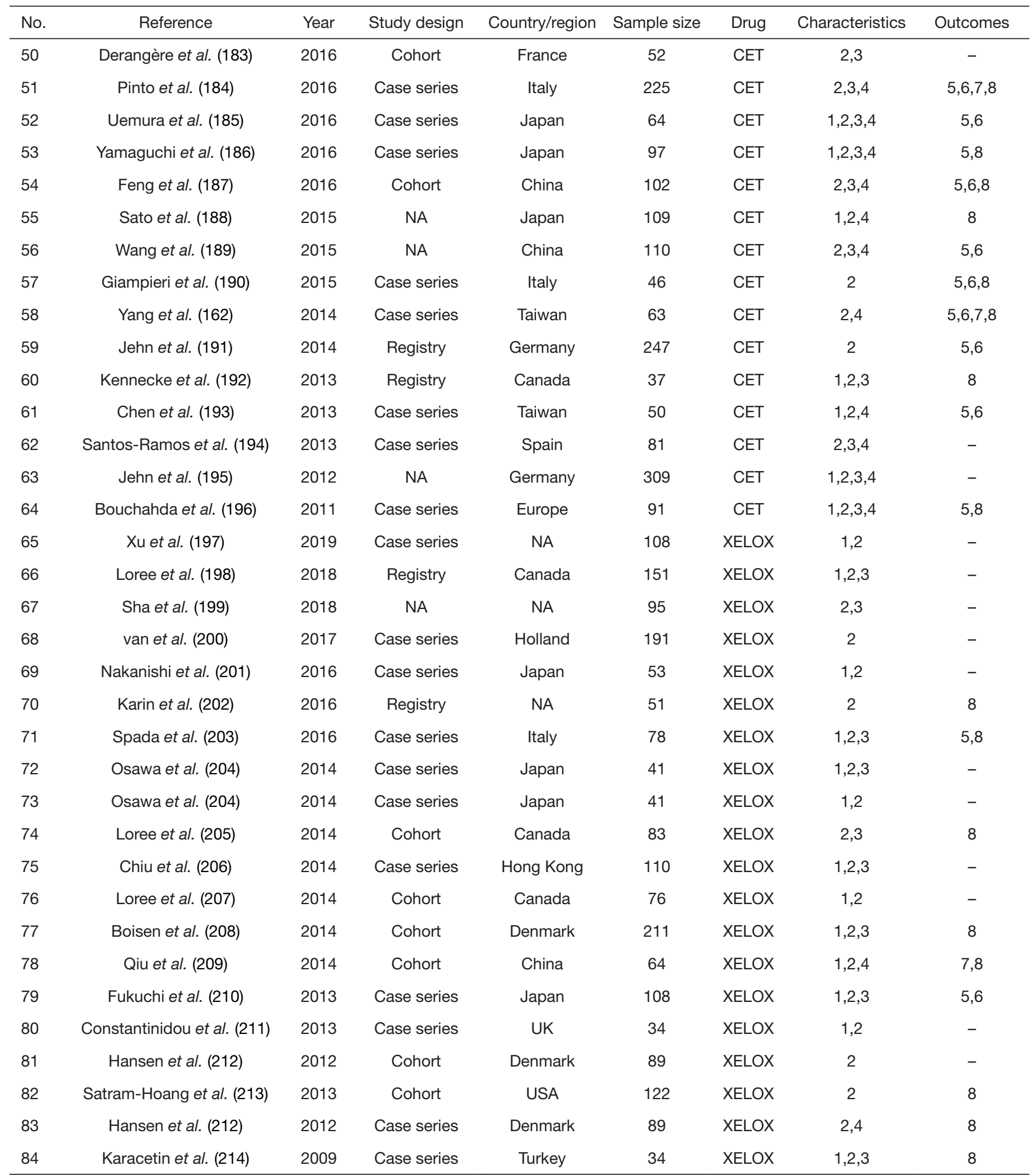

Age =1; gender =2; ECOG =3; treat-line =4; ORR =5; DCR =6; PFS =7; OS =8. UK, United Kingdom; USA, the United States of America; NA, not available; BEV, bevacizumab; CET, cetuximab; XELOX, oxaliplatin combined with capecitabine; ECOG, Eastern Cooperative Oncology Group. 
A

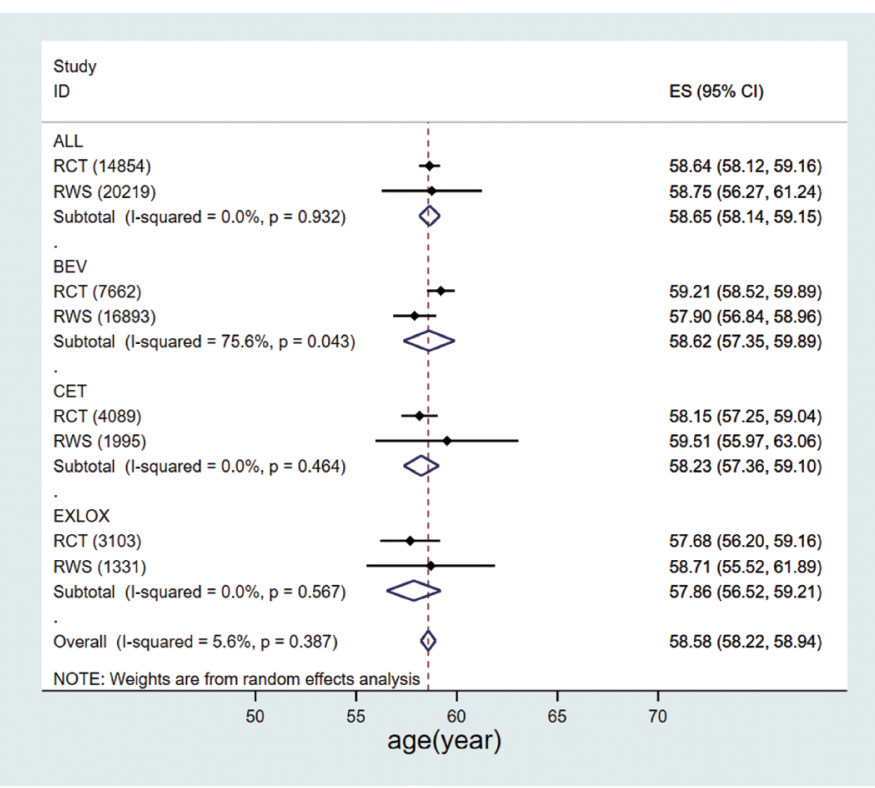

C

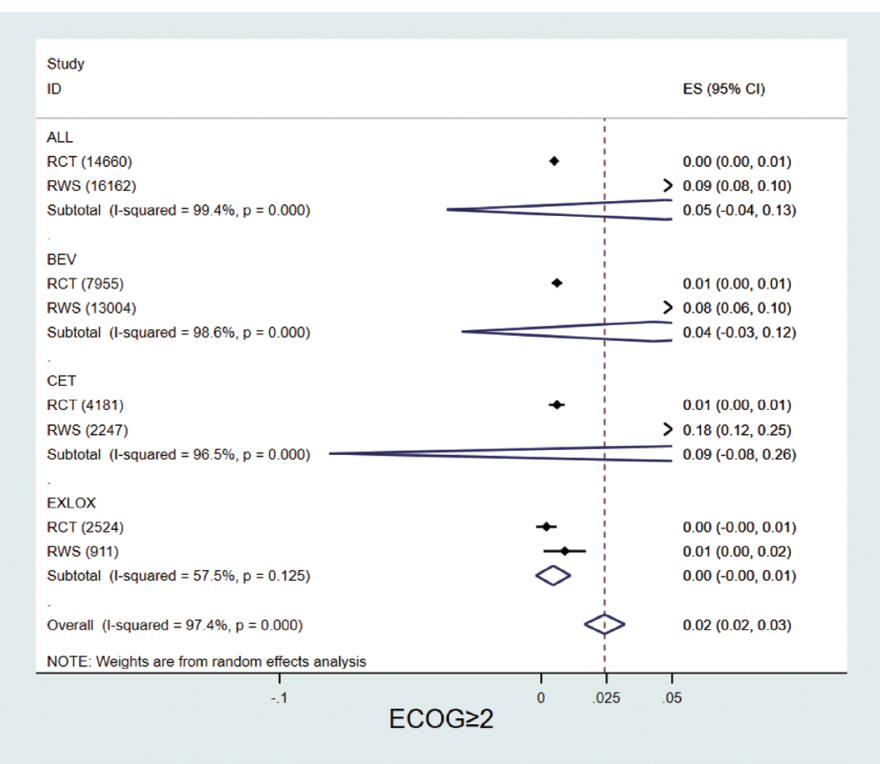

B

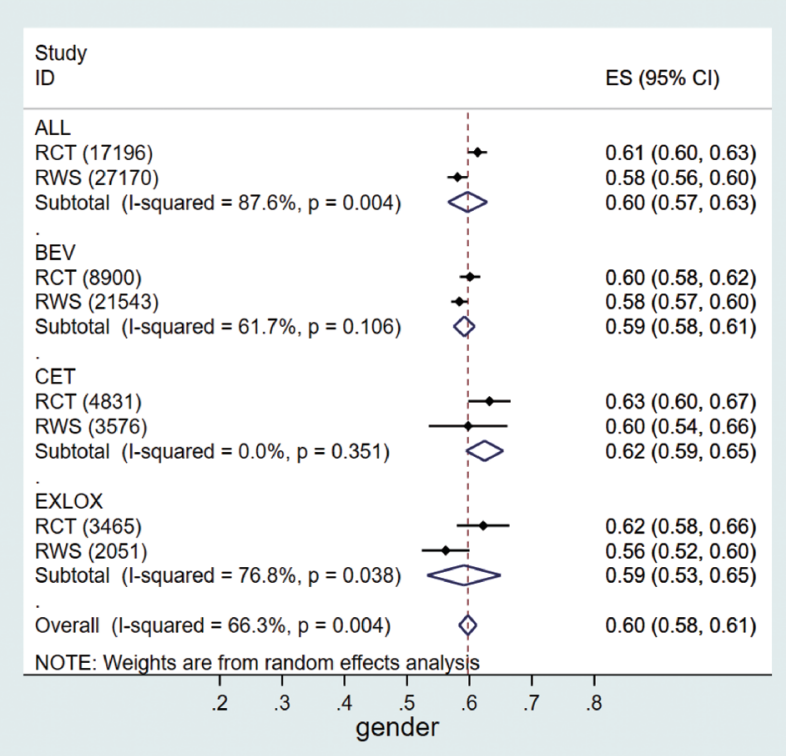

D

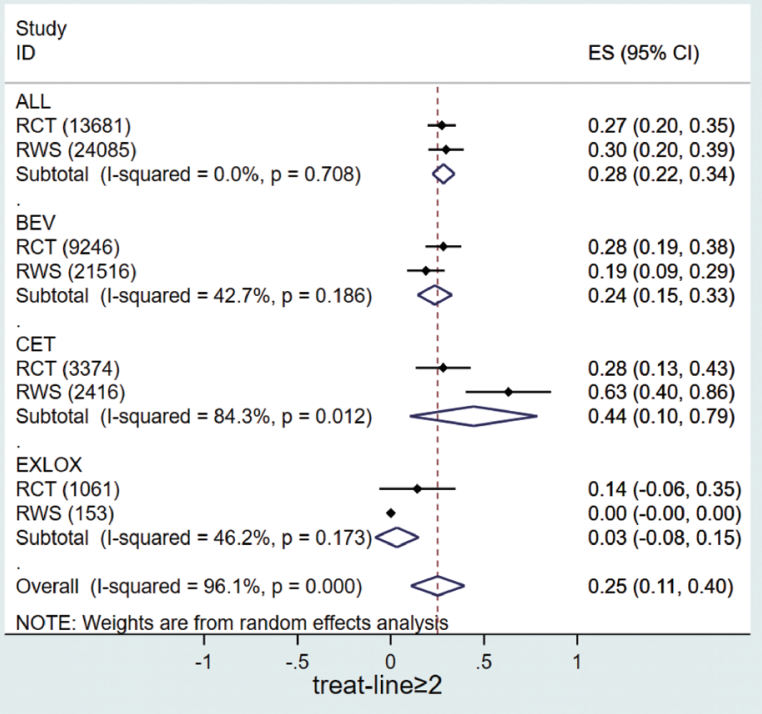

Figure 2 Comparison of patient characteristics. (A) Age; (B) gender; (C) ECOG $\geq 2$; (D) treat-line $\geq 2$. ECOG, Eastern Cooperative Oncology Group; RCT, randomized controlled trial; RWS, real-world studies; BEV, bevacizumab; CET, cetuximab; XELOX, oxaliplatin combined with capecitabine; ES, effect size; CI, confidence interval.

\section{Secondary outcomes}

No differences in ORR and DCR were found between RCTs and RWS by overall analysis and subgroup analysis in the BEV group and CET group. However, in the XELOX group, the ORR of patients in RCTs was 0.251 higher than that of patients in RWS $(0.563,0.457$ to 0.669 vs. 0.312 , 0.214 to $0.410 ; \mathrm{P}=0.001$ ), and DCR was also $20.6 \%$ higher than that of patients in RWS $(0.936,0.857$ to 1.016 vs. 0.730 , 0.646 to $0.814 ; \mathrm{P}=0.001$ ) (Figure 3). More detailed results show in Table S2 and Figures S9-S16. 
A

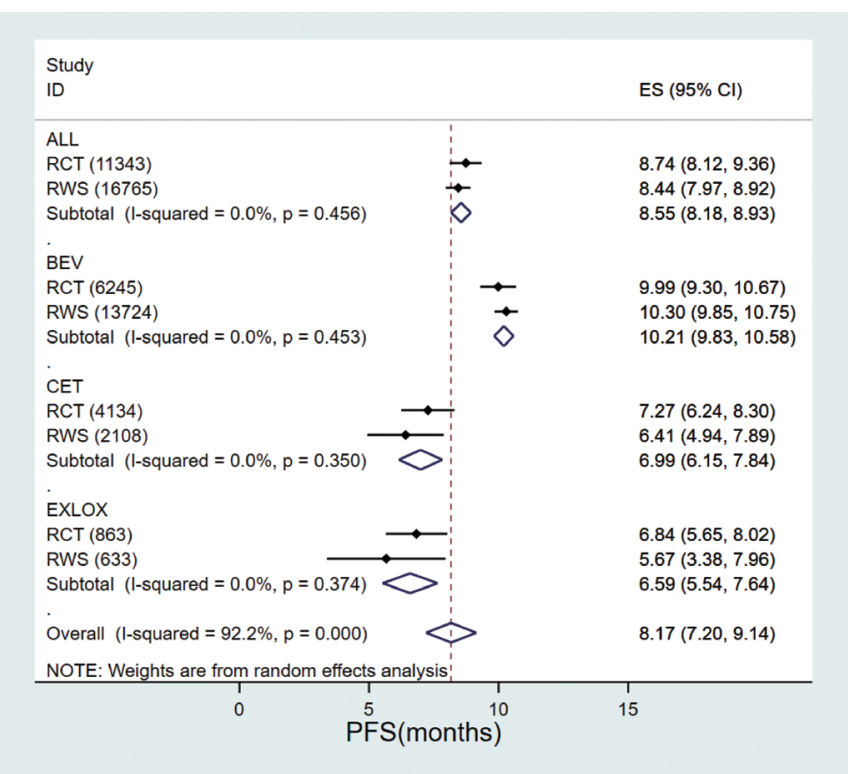

C

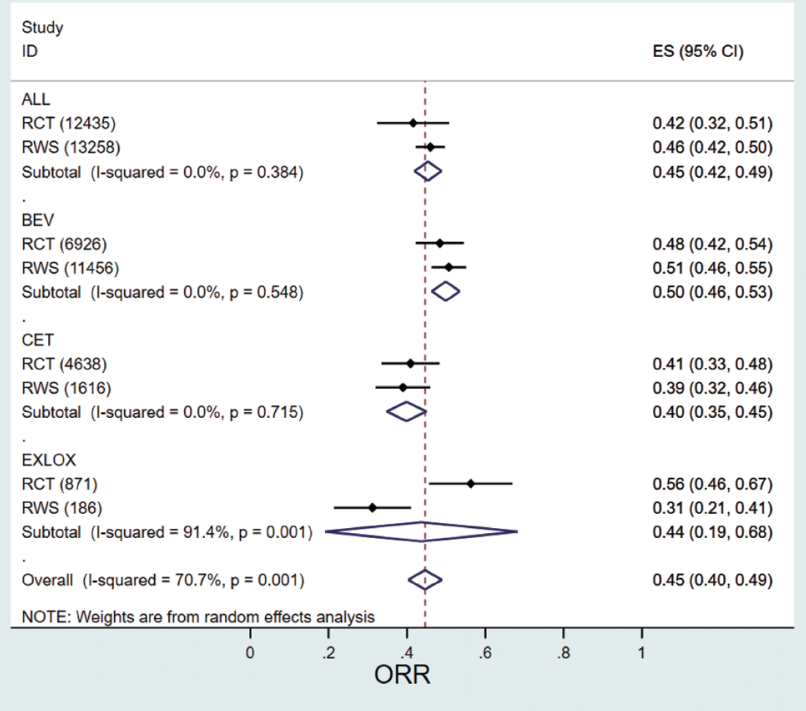

B

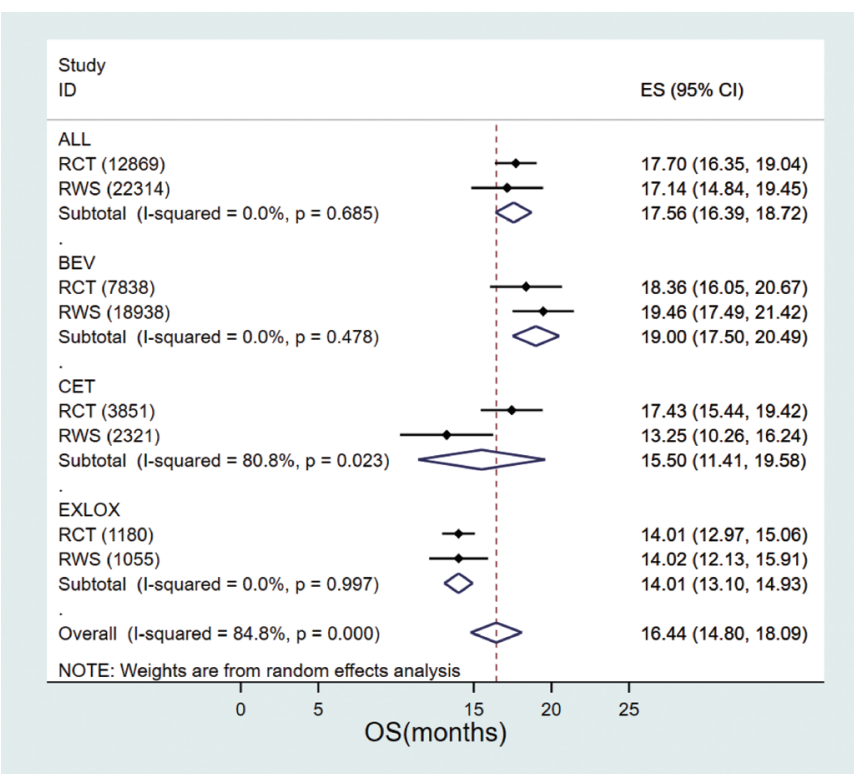

D

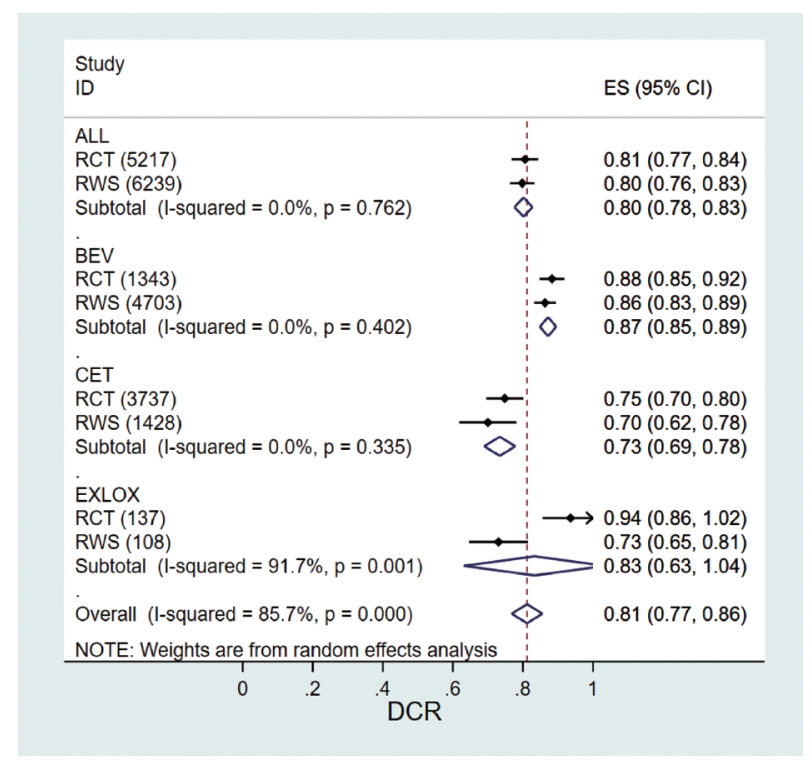

Figure 3 Comparison of treatment effects. (A) PFS; (B) OS; (C) ORR; (D) DCR. PFS, progression-free survival; OS, overall survival; ORR, objective response rate; DCR, disease control rate; RCT, randomized controlled trial; RWS, real-world studies; BEV, bevacizumab; CET, cetuximab; XELOX, oxaliplatin combined with capecitabine; ES, effect size; CI, confidence interval.

\section{Meta-regression analyses result}

According to the meta-analysis results, there were OS differences between RCT and RWS in the CET group, and ORR and DCR differences in the XELOX group.
Based on the previous analysis, we found no differences in age, gender, ethnicity and other baseline characteristics of the CET group, except for ECOG and treatment line. To explore the reason for OS differences, we performed metaregression analysis by including ECOG and treatment line 
Table 4 Regression analyses of OS in the CET group

\begin{tabular}{lccccc}
\hline OS & Coef. & Std. Err. & $\mathrm{t}$ & $\mathrm{P}$ & $95 \% \mathrm{Cl}$ \\
\hline Study type & 2.924438 & 2.812611 & 1.04 & 0.314 & -3.038031 to 8.886906 \\
Treatment line & 10.29738 & 2.341684 & -4.4 & 0.000 & -15.26153 to -5.333236 \\
ECOG & 2.644013 & 10.23937 & -0.26 & 0.800 & -24.3505 to 19.06248 \\
_cons & 21.47765 & 1.143907 & 18.78 & 0.000 & 19.05267 to 23.90262 \\
\hline
\end{tabular}

OS, overall survival; CET, cetuximab; Coef., coefficient; Std. Err., standard error; CI, confidence interval; ECOG, Eastern Cooperative Oncology Group.

Table 5 Regression analyses of ORR in the XELOX group

\begin{tabular}{lccccc}
\hline ORR & Coef. & Std. Err. & $\mathrm{t}$ & $\mathrm{P}$ & $95 \% \mathrm{Cl}$ \\
\hline Study type & -0.2529 & 0.112954 & -2.24 & 0.052 & -0.50842 to 0.002623 \\
Gender & 0.422701 & 0.484584 & 0.87 & 0.406 & -0.673505 to 1.518906 \\
_cons & 0.262381 & 0.294841 & 0.89 & 0.397 & -0.404595 to 0.929357 \\
\hline
\end{tabular}

ORR, objective response rate; XELOX, oxaliplatin combined with capecitabine; Coef., coefficient; Std. Err., standard error; Cl, confidence interval.

Table 6 Regression analyses of DCR in the XELOX group

\begin{tabular}{lccccc}
\hline DCR & Coef. & Std. Err. & $\mathrm{t}$ & $\mathrm{P}$ & $95 \% \mathrm{Cl}$ \\
\hline Study type & 0.0055461 & 0.0924147 & 0.06 & 0.962 & -1.168694 to 1.179786 \\
Gender & 1.428532 & 0.4492353 & 3.18 & 0.194 & -4.279555 to 7.136596 \\
_cons & 0.1183735 & 0.3428134 & -0.35 & 0.788 & -4.475501 to 4.238754 \\
\hline
\end{tabular}

DCR, disease control rate; XELOX, oxaliplatin combined with capecitabine; Coef., coefficient; Std. Err., standard error; Cl, confidence interval.

as covariates, OS as dependent variables in the CET group. We extracted the proportion of patients with ECOG score $\geq 2$, and the proportion of patients with second-line or above treatment, based on baseline data from the original study. And there were only gender differences in the XELOX group, so we included the proportion of male patients as covariates, ORR and DCR as the dependent variable in the XELOX group. To explore the impact of study design on results, included the study design as a dichotomous covariate in both groups.

The regression results showed that OS differences in the CET group were related to the difference of treatment line and were not related to ECOG and study type (Table 4). In the XELOX group, differences in treatment outcomes were independent of baseline characteristics and study type (Tables 5,6).

In addition, although the case number of RWS reporting follow-up time, treatment cycle, and duration was lower than that of RCT, the $t$-test results for mean follow-up time, treatment cycle, and duration between RCT and RWS showed no significant difference (Table 7).

\section{Discussion}

\section{Key findings}

In this systematic review and meta-analysis, we found that there were slight systematic differences in patient characteristics between RCTs and RWS in CRC. The differences in baseline characteristics mainly included a higher proportion of male patients, a lower proportion of patients with ECOG score $\geq 2$, and a lower proportion of second-line and above-second-line treatments in RCT. The reasons for these differences may be as follows: For gender, data on CRC patients collected from the Medicare 
Table 7 T-test of follow up time, treatment cycle and duration

\begin{tabular}{lccccc}
\hline$T$-test & Study type & Case number & Mean & SD & P value \\
\hline Follow up time/month & RCT & 56 & 29.6352 & 16.40549 & 2.19228 \\
& RWS & 38 & 26.0416 & 11.32764 & 0.244 \\
Treatment cycle & RCT & 35 & 7.37143 & 2.587705 & 2.624251 \\
& RWS & 18 & 7.31383 & 0.939 \\
Treatment duration/month & RCT & 24 & 4.8875 & 2.47607 & 0.940 \\
& RWS & 12 & 5.7408 & 4.23496 \\
\hline
\end{tabular}

RCT, randomized controlled trial; RWS, real-world study; SD, standard.

database show that the proportion of men with CRC is generally higher than that of women, however, as the sample size increases, the difference will be narrowed, since the sample size of RWS is much larger than that of RCT, the proportion of male patients in RWS is closer to $50 \%$. In addition, according to a study, men are more likely to participate in RCTs than women (215), which also leaded to a higher proportion of male patients in RCT than RWS. For ECOG score and treatment line, RCT has more strict inclusion and exclusion criteria for patients. Patients with high ECOG score and above-second-line treatments may be excluded due to poor health status and complex medical history. Therefore, the proportion of patients with ECOG score $\geq 2$ and second-line and above-second-line treatments in RCT is lower.

Although there were slight differences in baseline characteristics, it did not lead to any difference in treatment outcomes by overall analysis, indicating that the results of RCT and RWS were highly consistent. As for the partial differences in subgroup analysis, a further meta-regression analysis showed that the higher OS value in the CET group of RCTs were due to the inclusion of more patients who are treated in frontlines, that can be reasonably interpreted as patients treated in frontlines were in better health. But no reason was found for the difference between ORR and DCR in XELOX group due to the small number of studies and the serious lack of clinical outcome data. We suggest conducting high-quality XELOX RWS for CRC patients in the future to supplement the deficiencies of the existing research.

\section{Strengths and implications}

This comparative study focused on cancer, the anticancer treatment process had relatively high standardization in drug regimens, drug compliance, and strict monitoring measures of toxicity and adverse reaction $(216,217)$, which greatly reduced the differences in intervention measures and patients' drug compliance and also lowered the bias of the results. Compared with several studies in the past, regression analysis was added in this study to determine the correlation between differences in baseline characteristics and differences in treatment effects, and rule out the effect of study design on the results. We believe that the differences between RCTs and RWS in different disease areas cannot be generalized. This study will be more applicable to clarify the external validity of RCTs results for CRC in real-world applications, help understanding the current status in CRC, improving research design and providing decision-making references for health decisionmaking departments.

\section{Limitations}

Given that this study mainly focused on the differences in patient characteristics between RCTs and RWS rather than the results of clinical trials, we did not perform quality assessment on the literature, the RWS across different countries may result in potential confounding factors. Since the OS value did not reach the upper limit in some studies, we used conservative estimation in the analysis to assume the OS values as the longest follow-up time in this study, which may lead to the underestimation of the OS values. Due to the limitations of study time, study number, and quality of the included studies, the conclusion herein need further verification.

\section{Conclusions}

No efficacy-effectiveness gap was found in CRC between 
RCTs and RWS. The treatment effects of RCTs and RWS in CRC patients were highly consistent, and the results of RCTs have high external validity.

\section{Acknowledgments}

We thank our colleagues at Center for Pharmacoeconomics and Outcomes Research of China pharmaceutical university, for their scientific advice, assistance in data analysis and contribution to translation the paper.

Funding: None.

\section{Footnote}

Reporting Checklist: The authors have completed the PRISMA reporting checklist. Available at http://dx.doi. org/10.21037/tcr-20-2303

Conflicts of Interest: All authors have completed the ICMJE uniform disclosure form (available at http://dx.doi. org/10.21037/tcr-20-2303). The authors have no conflicts of interest to declare.

Ethical Statement: The authors are accountable for all aspects of the work in ensuring that questions related to the accuracy or integrity of any part of the work are appropriately investigated and resolved.

Open Access Statement: This is an Open Access article distributed in accordance with the Creative Commons Attribution-NonCommercial-NoDerivs 4.0 International License (CC BY-NC-ND 4.0), which permits the noncommercial replication and distribution of the article with the strict proviso that no changes or edits are made and the original work is properly cited (including links to both the formal publication through the relevant DOI and the license). See: https://creativecommons.org/licenses/by-nc-nd/4.0/.

\section{References}

1. Chen YL, Li YP, Du L, et al. Evolution of levels of evidence and strength of recommendations in medical research. Chinese Journal of Evidence-Based Medicine 2008;8:127-33.

2. Yim EY, Lim SH, Oh MJ, et al. Assessment of pharmacoeconomic evaluations submitted for reimbursement in Korea. Value Health 2012;15:S104-10.

3. Berger ML, Martin BC, Husereau D, et al. A questionnaire to assess the relevance and credibility of observational studies to inform health care decision making: an ISPORAMCP-NPC Good Practice Task Force report. Value Health 2014;17:143-56.

4. Gabay M. 21st Century Cures Act. Hosp Pharm 2017;52:264-5

5. Real-World Evidence Program.

6. Jaksa A. Does real world evidence matter in Health Technology Assessments? 2015.

7. Naudet F, Maria AS, Falissard B. Antidepressant response in major depressive disorder: a meta-regression comparison of randomized controlled trials and observational studies. PLoS One 2011;6:e20811.

8. Kilcher G, Hummel N, Didden EM, et al. Rheumatoid arthritis patients treated in trial and real world settings: comparison of randomized trials with registries. Rheumatology 2018;57:354-69.

9. Gray E, Norris S, Schmitz S, et al. Do disparities between populations in randomized controlled trials and the real world lead to differences in outcomes? J Comp Eff Res 2017;6:65-82.

10. Bahit MC, Cannon CP, Antman EM, et al. Direct comparison of characteristics, treatment, and outcomes of patients enrolled versus patients not enrolled in a clinical trial at centers participating in the TIMI 9 Trial and TIMI 9 Registry. Am Heart J 2003;145:109-17.

11. Ezekowitz JA, Hu J, Delgado D, et al. Acute heart failure: perspectives from a randomized trial and a simultaneous registry. Circ Heart Fail 2012;5:735-41.

12. Lopes RD, Leonardi S, Neely B, et al. Spontaneous MI after non-ST-segment elevation acute coronary syndrome managed without revascularization. J Am Coll Cardiol 2016;67:1289-97.

13. Benson K, Hartz AJ. A comparison of observational studies and randomized, controlled trials. $\mathrm{N}$ Engl J Med 2000;342:1878-86.

14. Concato J, Shah N, Horwitz RI. Randomized, controlled trials, observational studies, and the hierarchy of research designs. N Engl J Med 2000;342:1887-92.

15. Flossmann E, Rothwell PM. Effect of aspirin on longterm risk of colorectal cancer: consistent evidence from randomised and observational studies. Lancet 2007;369:1603-13.

16. Lonjon G, Boutron I, Trinquart L, et al. Comparison of treatment effect estimates from prospective nonrandomized studies with propensity score analysis and randomized controlled trials of surgical procedures. Ann Surg 2014;259:18-25. 
17. Edwards JP, Kelly EJ, Lin Y, et al. Meta-analytic comparison of randomized and nonrandomized studies of breast cancer surgery. Can J Surg 2012;55:155-62.

18. van Heesewijk AE, Rush ML, Schmidt B, et al. Agreement between study designs: a systematic review comparing observational studies and randomized trials of surgical treatments for necrotizing enterocolitis. J Matern Fetal Neonatal Med 2020;33:1965-73.

19. Benson AB 3rd, Venook AP, Cederquist L, et al. Colon Cancer, Version 1.2017, NCCN Clinical Practice Guidelines in Oncology. J Natl Compr Canc Netw 2017;15:370-98.

20. Medical Administration and Hospital Administration of the National Health and Family Planning Commission of the People's Republic of China; Chinese Medical Association Oncology Branch. Chinese colorectal cancer diagnosis and treatment standard (2017 edition). Chin J Pract Surg 2018;38:1089-103.

21. Wan X, Wang W, Liu J, et al. Estimating the sample mean and standard deviation from the sample size, median, range and/or interquartile range. BMC Med Res Methodol 2014;14:135.

22. Knapp G, Hartung J. Improved tests for a random effects meta-regression with a single covariate. Stat Med 2003;22:2693-710.

23. Kim Y, Kim TW, Han SW, et al. A single arm, phase II study of simvastatin plus XELOX and bevacizumab as first-line chemotherapy in metastatic colorectal cancer patients. Cancer Res Treat 2019;51:1128-34.

24. Cremolini C, Marmorino F, Bergamo F, et al. Phase II randomised study of maintenance treatment with bevacizumab or bevacizumab plus metronomic chemotherapy after first-line induction with FOLFOXIRI plus Bevacizumab for metastatic colorectal cancer patients: the MOMA trial. Eur J Cancer 2019;109:175-82.

25. Suzuki N, Hazama S, Nagasaka T, et al. Multicenter phase II study of biweekly CAPIRI plus bevacizumab as secondline therapy in patients with metastatic colorectal cancer (JSWOG-C3 study). Int J Clin Oncol 2019;24:1223-30.

26. Nakayama G, Mitsuma A, Sunagawa Y, et al. Randomized Phase II Trial of CapOX plus Bevacizumab and CapIRI plus Bevacizumab as First-Line Treatment for Japanese Patients with Metastatic Colorectal Cancer (CCOG-1201 Study). Oncologist 2018;23:919-27.

27. Oki E, Kato T, Bando H, et al. A multicenter clinical phase II study of FOLFOXIRI plus bevacizumab as firstline therapy in patients with metastatic colorectal cancer: QUATTRO study. Clin Colorectal Cancer 2018;17:147-55.
28. Jonker DJ, Tang PA, Kennecke H, et al. A randomized phase II study of FOLFOX6/bevacizumab with or without pelareorep in patients with metastatic colorectal cancer: IND.210, a Canadian Cancer Trials Group Trial. Clin Colorectal Cancer 2018;17:231-9.e7.

29. Satake H, Sunakawa Y, Miyamoto Y, et al. A phase II trial of 1st-line modified-FOLFOXIRI plus bevacizumab treatment for metastatic colorectal cancer harboring RAS mutation: JACCRO CC-11. Oncotarget 2018;9:18811-20.

30. Matsuda C, Honda M, Tanaka C, et al. A phase II study of bevacizumab and irinotecan plus alternate-day $\mathrm{S}-1$ as a second-line therapy in patients with metastatic colorectal cancer: the AIRS study. Cancer Chemother Pharmacol 2018;81:1035-41.

31. Ulivi P, Canale M, Passardi A, et al. Circulating plasma levels of miR-20b, miR-29b and miR-155 as predictors of bevacizumab efficacy in patients with metastatic colorectal cancer. Int J Mol Sci 2018;19:307.

32. Venook AP, Niedzwiecki D, Lenz HJ, et al. Effect of first-line chemotherapy combined with cetuximab or bevacizumab on overall survival in patients with KRAS wild-type advanced or metastatic colorectal cancer: a randomized clinical trial. JAMA. 2017;317:2392-401.

33. Nakayama G, Ishigure K, Yokoyama H, et al. The efficacy and safety of CapeOX plus bevacizumab therapy followed by capecitabine plus bevacizumab maintenance therapy in patients with metastatic colorectal cancer: a multi-center, single-arm, phase II study (CCOG-0902). BMC Cancer 2017;17:243.

34. Apsangikar PD, Chaudhry SR, Naik MM, et al. Comparative pharmacokinetics, efficacy, and safety of bevacizumab biosimilar to reference bevacizumab in patients with metastatic colorectal cancer. Indian J Cancer 2017;54:535-8.

35. Zhao Z, Li J, Ye R, et al. A phase II clinical study of combining FOLFIRI and bevacizumab plus erlotinib in 2nd-line chemotherapy for patients with metastatic colorectal cancer. Medicine (Baltimore) 2017;96:e7182.

36. Baba H, Yamada Y, Takahari D, et al. S-1 and oxaliplatin (SOX) plus bevacizumab versus mFOLFOX6 plus bevacizumab as first-line treatment for patients with metastatic colorectal cancer: updated overall survival analyses of the open-label, non-inferiority, randomised phase III: SOFT study. ESMO Open 2017;2:e000135.

37. Matsui T, Nagata N, Hirata K, et al. Bi-weekly capecitabine-oxaliplatin (XELOX) plus bevacizumab as first-line treatment of metastatic colorectal cancer--the PHOENiX trial. Anticancer Res 2016;36:3437-43. 
38. Ogata Y, Shimokawa M, Tanaka T, et al. A prospective study of XELOX plus bevacizumab as first-line therapy in Japanese patients with metastatic colorectal cancer (KSCC 0902). Int J Clin Oncol 2016;21:335-43.

39. Yamazaki K, Nagase M, Tamagawa H, et al. Randomized phase III study of bevacizumab plus FOLFIRI and bevacizumab plus mFOLFOX6 as first-line treatment for patients with metastatic colorectal cancer (WJOG4407G). Ann Oncol 2016;27:1539-46.

40. van Hazel GA, Heinemann V, Sharma NK, et al. SIRFLOX: randomized phase III trial comparing firstline mFOLFOX6 (plus or minus bevacizumab) versus mFOLFOX6 (plus or minus bevacizumab) plus selective internal radiation therapy in patients with metastatic colorectal cancer. J Clin Oncol 2016;34:1723-31.

41. Stintzing S, Modest DP, Rossius L, et al. FOLFIRI plus cetuximab versus FOLFIRI plus bevacizumab for metastatic colorectal cancer (FIRE-3): a post-hoc analysis of tumour dynamics in the final RAS wild-type subgroup of this randomised open-label phase 3 trial. Lancet Oncol 2016;17:1426-34.

42. Shitara K, Yonesaka K, Denda T, et al. Randomized study of FOLFIRI plus either panitumumab or bevacizumab for wild-type KRAS colorectal cancer-WJOG 6210G. Cancer Sci 2016;107:1843-50.

43. Hagman H, Frodin JE, Berglund A, et al. A randomized study of KRAS-guided maintenance therapy with bevacizumab, erlotinib or metronomic capecitabine after first-line induction treatment of metastatic colorectal cancer: the Nordic ACT2 trial. Ann Oncol 2016;27:140-7.

44. Benson AB 3rd, Kiss I, Bridgewater J, et al. BATONCRC: A phase II randomized trial comparing tivozanib plus mFOLFOX6 with bevacizumab plus mFOLFOX6 in stage IV metastatic colorectal cancer. Clin Cancer Res 2016;22:5058-67.

45. Shimomura M, Shinozaki K, Hinoi T, et al. A multiinstitutional feasibility study of S-1/oxaliplatin plus bevacizumab in patients with advanced/metastatic colorectal cancer: the HiSCO-02 prospective phase II study. Springerplus 2016;5:1800.

46. Passardi A, Nanni O, Tassinari D, et al. Effectiveness of bevacizumab added to standard chemotherapy in metastatic colorectal cancer: final results for first-line treatment from the ITACa randomized clinical trial. Ann Oncol 2015;26:1201-7.

47. Antonuzzo L, Giommoni E, Pastorelli D, et al. Bevacizumab plus XELOX as first-line treatment of metastatic colorectal cancer: the OBELIX study. World J
Gastroenterol 2015;21:7281-8.

48. Iwamoto $S$, Takahashi T, Tamagawa H, et al. FOLFIRI plus bevacizumab as second-line therapy in patients with metastatic colorectal cancer after first-line bevacizumab plus oxaliplatin-based therapy: the randomized phase III EAGLE study. Ann Oncol 2015;26:1427-33.

49. Hegewisch-Becker S, Graeven U, Lerchenmuller CA, et al. Maintenance strategies after first-line oxaliplatin plus fluoropyrimidine plus bevacizumab for patients with metastatic colorectal cancer (AIO 0207): a randomised, non-inferiority, open-label, phase 3 trial. Lancet Oncol 2015;16:1355-69.

50. Masi G, Salvatore L, Boni L, et al. Continuation or reintroduction of bevacizumab beyond progression to firstline therapy in metastatic colorectal cancer: final results of the randomized BEBYP trial. Ann Oncol 2015;26:724-30.

51. Cao R, Zhang S, Ma D, et al. A multi-center randomized phase II clinical study of bevacizumab plus irinotecan, 5-fluorouracil, and leucovorin (FOLFIRI) compared with FOLFIRI alone as second-line treatment for Chinese patients with metastatic colorectal cancer. Med Oncol 2015;32:325.

52. Wang G, Ye Y, Zhang X, et al. A single-arm clinical study of continuous usage of bevacizumab as secondline chemotherapy for Chinese patients with metastatic colorectal cancer. Med Oncol 2015;32:163.

53. Garcia-Alfonso P, Chaves M, Munoz A, et al. Capecitabine and irinotecan with bevacizumab 2-weekly for metastatic colorectal cancer: the phase II AVAXIRI study. BMC Cancer 2015;15:327.

54. Liu Y, Luan L, Wang X. A randomized Phase II clinical study of combining panitumumab and bevacizumab, plus irinotecan, 5-fluorouracil, and leucovorin (FOLFIRI) compared with FOLFIRI alone as second-line treatment for patients with metastatic colorectal cancer and KRAS mutation. Onco Targets Ther 2015;8:1061-8.

55. Nakayama N, Sato A, Tanaka S, et al. A phase II study of bevacizumab with modified OPTIMOX1 as first-line therapy for metastatic colorectal cancer: the TCOG-GI 0802 study. Invest New Drugs 2015;33:954-62.

56. Heinemann V, von Weikersthal LF, Decker T, et al. FOLFIRI plus cetuximab versus FOLFIRI plus bevacizumab as first-line treatment for patients with metastatic colorectal cancer (FIRE-3): a randomised, open-label, phase 3 trial. Lancet Oncol 2014;15:1065-75.

57. Duran AO, Karaca H, Besiroglu M, et al. XELOX plus bevacizumab vs. FOLFIRI plus bevacizumab treatment for first-line chemotherapy in metastatic colon cancer: a 
retrospective study of the Anatolian Society of Medical Oncology. Asian Pac J Cancer Prev 2014;15:10375-9.

58. O'Neil BH, Cainap C, Van Cutsem E, et al. Randomized phase II open-label study of mFOLFOX6 in combination with linifanib or bevacizumab for metastatic colorectal cancer. Clin Colorectal Cancer 2014;13:156-63.e2.

59. Uygun K, Bilici A, Kaya S, et al. XELIRI plus bevacizumab compared with FOLFIRI plus bevacizumab as firstline setting in patients with metastatic colorectal cancer: experiences at two-institutions. Asian Pac J Cancer Prev 2013;14:2283-8.

60. Schmiegel W, Reinacher-Schick A, Arnold D, et al. Capecitabine/irinotecan or capecitabine/oxaliplatin in combination with bevacizumab is effective and safe as firstline therapy for metastatic colorectal cancer: a randomized phase II study of the AIO colorectal study group. Ann Oncol 2013;24:1580-7.

61. Kochi M, Akiyama Y, Aoki T, et al. FOLFIRI plus bevacizumab as a first-line treatment for Japanese patients with metastatic colorectal cancer: a JACCRO CC-03 multicenter phase II study. Cancer Chemother Pharmacol 2013;72:1097-102.

62. Bennouna J, Sastre J, Arnold D, et al. Continuation of bevacizumab after first progression in metastatic colorectal cancer (ML18147): a randomised phase 3 trial. Lancet Oncol 2013;14:29-37.

63. Ducreux M, Adenis A, Pignon JP, et al. Efficacy and safety of bevacizumab-based combination regimens in patients with previously untreated metastatic colorectal cancer: Final results from a randomised phase ii study of bevacizumab plus 5 -fluorouracil, leucovorin plus irinotecan versus bevacizum. Eur J Cancer 2013;49:1236-45.

64. Cunningham D, Wong RP, D'Haens G, et al. Cediranib with mFOLFOX6 vs bevacizumab with mFOLFOX6 in previously treated metastatic colorectal cancer. Br J Cancer 2013;108:493-502.

65. Yalcin S, Uslu R, Dane F, et al. Bevacizumab + capecitabine as maintenance therapy after initial bevacizumab + XELOX treatment in previously untreated patients with metastatic colorectal cancer: phase III 'Stop and Go' study results--a Turkish Oncology Group Trial. Oncology 2013;85:328-35.

66. Johnsson A, Hagman H, Frödin JE, et al. A randomized phase III trial on maintenance treatment with bevacizumab alone or in combination with erlotinib after chemotherapy and bevacizumab in metastatic colorectal cancer: the Nordic ACT Trial. Ann Oncol 2013;24:2335-41.

67. Hong YS, Lee J, Kim KP, et al. Multicenter phase II study of second-line bevacizumab plus doublet combination chemotherapy in patients with metastatic colorectal cancer progressed after upfront bevacizumab plus doublet combination chemotherapy. Invest New Drugs 2013;31:183-91.

68. Stintzing S, Fischer VWL, Decker T, et al. FOLFIRI plus cetuximab versus FOLFIRI plus bevacizumab as first-line treatment for patients with metastatic colorectal cancersubgroup analysis of patients with KRAS: mutated tumours in the randomised German AIO study KRK-0306. Ann Oncol 2012;23:1693-9.

69. Pectasides D, Papaxoinis G, Kalogeras KT, et al. XELIRIbevacizumab versus FOLFIRI-bevacizumab as first-line treatment in patients with metastatic colorectal cancer: a Hellenic Cooperative Oncology Group phase III trial with collateral biomarker analysis. BMC Cancer 2012;12:271.

70. Díaz-Rubio E, Gómez-España A, Massutí B, et al. Firstline XELOX plus bevacizumab followed by XELOX plus bevacizumab or single-agent bevacizumab as maintenance therapy in patients with metastatic colorectal cancer: the phase III MACRO TTD study. Oncologist 2012;17:15-25.

71. Hurwitz H, Mitchell EP, Cartwright T, et al. A randomized, phase II trial of standard triweekly compared with dose-dense biweekly capecitabine plus oxaliplatin plus bevacizumab as first-line treatment for metastatic colorectal cancer: XELOX-A-DVS (dense versus standard). Oncologist 2012;17:937-46.

72. Renouf DJ, Welch S, Moore MJ, et al. A phase II study of capecitabine, irinotecan, and bevacizumab in patients with previously untreated metastatic colorectal cancer. Cancer Chemother Pharmacol 2012;69:1339-44.

73. Wolff RA, Fuchs M, Di Bartolomeo M, et al. A doubleblind, randomized, placebo-controlled, phase 2 study of maintenance enzastaurin with 5 -fluorouracil/leucovorin plus bevacizumab after first-line therapy for metastatic colorectal cancer. Cancer 2012;118:4132-8.

74. Tang PA, Cohen SJ, Kollmannsberger C, et al. Phase II clinical and pharmacokinetic study of aflibercept in patients with previously treated metastatic colorectal cancer. Clin Cancer Res 2012;18:6023-31.

75. Yamada Y, Yamaguchi T, Matsumoto H, et al. Phase II study of oral S-1 with irinotecan and bevacizumab (SIRB) as first-line therapy for patients with metastatic colorectal cancer. Invest New Drugs 2012;30:1690-6.

76. Wong NS, Fernando NH, Bendell JC, et al. A phase II study of oxaliplatin, dose-intense capecitabine, and highdose bevacizumab in the treatment of metastatic colorectal cancer. Clin Colorectal Cancer 2011;10:210-6. 
77. Guan ZZ, Xu JM, Luo RC, et al. Efficacy and safety of bevacizumab plus chemotherapy in Chinese patients with metastatic colorectal cancer: a randomized phase III ARTIST trial. Chin J Cancer 2011;30:682-9.

78. Altomare I, Bendell JC, Bullock KE, et al. A phase II trial of bevacizumab plus everolimus for patients with refractory metastatic colorectal cancer. Oncologist 2011;16:1131-7.

79. Kopetz S, Hoff PM, Morris JS, et al. Phase II trial of infusional fluorouracil, irinotecan, and bevacizumab for metastatic colorectal cancer: efficacy and circulating angiogenic biomarkers associated with therapeutic resistance. J Clin Oncol 2010;28:453-9.

80. Bruera G, Santomaggio A, Cannita K, et al. "Poker" association of weekly alternating 5-fluorouracil, irinotecan, bevacizumab and oxaliplatin (FIr-B/FOx) in first line treatment of metastatic colorectal cancer: a phase II study. BMC Cancer 2010;10:567.

81. Masi G, Loupakis F, Salvatore L, et al. Bevacizumab with FOLFOXIRI (irinotecan, oxaliplatin, fluorouracil, and folinate) as first-line treatment for metastatic colorectal cancer: a phase 2 trial. Lancet Oncol 2010;11:845-52.

82. Tebbutt NC, Wilson K, Gebski VJ, et al. Capecitabine, bevacizumab, and mitomycin in first-line treatment of metastatic colorectal cancer: results of the Australasian Gastrointestinal Trials Group Randomized Phase III MAX Study. J Clin Oncol 2010;28:3191-8.

83. Aranda E, Garcia-Alfonso P, Benavides M, et al. Firstline mFOLFOX plus cetuximab followed by mFOLFOX plus cetuximab or single-agent cetuximab as maintenance therapy in patients with metastatic colorectal cancer: phase II randomised MACRO2 TTD study. Eur J Cancer 2018;101:263-72.

84. Kotake M, Aoyama T, Munemoto Y, et al. Multicenter phase II study of infusional 5-fluorouracil (5-FU), leucovorin, and oxaliplatin, plus biweekly cetuximab as first-line treatment in patients with metastatic colorectal cancer (CELINE trial). Oncol Lett 2017;13:747-53.

85. Kataoka M, Kanda M, Ishigure K, et al. The COMET open-label phase II study of neoadjuvant FOLFOX or XELOX treatment combined with molecular targeting monoclonal antibodies in patients with resectable liver metastasis of colorectal cancer. Ann Surg Oncol 2017;24:546-53

86. Hazama S, Maeda H, Iwamoto S, et al. A phase II study of XELOX and cetuximab as first-line therapy in patients with KRAS wild type metastatic colorectal cancer (FLEET2 study). Clin Colorectal Cancer 2016;15:329-36.

87. Bowles DW, Kochenderfer M, Cohn A, et al. A randomized, phase II Trial of cetuximab with or without PX-866, an irreversible oral phosphatidylinositol 3-kinase inhibitor, in patients with metastatic colorectal carcinoma. Clin Colorectal Cancer 2016;15:337-44.e2.

88. Ciardiello F, Normanno N, Martinelli E, et al. Cetuximab continuation after first progression in metastatic colorectal cancer (CAPRI-GOIM): a randomized phase II trial of FOLFOX plus cetuximab versus FOLFOX. Ann Oncol 2016;27:1055-61.

89. Eng C, Bessudo A, Hart LL, et al. A randomized, placebocontrolled, phase 1/2 study of tivantinib (ARQ 197) in combination with irinotecan and cetuximab in patients with metastatic colorectal cancer with wild-type KRAS who have received first-line systemic therapy. Int J Cancer 2016;139:177-86.

90. Soda H, Maeda H, Hasegawa J, et al. Multicenter Phase II study of FOLFOX or biweekly XELOX and Erbitux (cetuximab) as first-line therapy in patients with wild-type KRAS/BRAF metastatic colorectal cancer: the FLEET study. BMC Cancer 2015;15:695.

91. Sclafani F, Kim TY, Cunningham D, et al. A randomized phase II/III study of dalotuzumab in combination with cetuximab and irinotecan in chemorefractory, KRAS wildtype, metastatic colorectal cancer. J Natl Cancer Inst 2015;107:djv258.

92. Do K, Cao L, Kang Z, et al. A phase II study of sorafenib combined with cetuximab in EGFR-expressing, KRASmutated metastatic colorectal cancer. Clin Colorectal Cancer 2015;14:154-61.

93. Élez E, Kocáková I, Höhler T, et al. Abituzumab combined with cetuximab plus irinotecan versus cetuximab plus irinotecan alone for patients with KRAS wild-type metastatic colorectal cancer: the randomised phase I/II POSEIDON trial. Ann Oncol 2015;26:132-40.

94. Fernandez-Plana J, Pericay C, Quintero G, et al. Biweekly cetuximab in combination with FOLFOX-4 in the firstline treatment of wild-type KRAS metastatic colorectal cancer: final results of a phase II, open-label, clinical trial (OPTIMIX-ACROSS Study). BMC Cancer 2014;14:865.

95. Iwamoto S, Hazama S, Kato T, et al. Multicenter phase II study of second-line cetuximab plus folinic acid/5fluorouracil/irinotecan (FOLFIRI) in KRAS wild-type metastatic colorectal cancer: the FLIER study. Anticancer Res 2014;34:1967-73.

96. Douillard JY, Zemelka T, Fountzilas G, et al. FOLFOX4 with cetuximab vs. UFOX with cetuximab as first-line therapy in metastatic colorectal cancer: the randomized phase II FUTURE study. Clin Colorectal Cancer 
2014;13:14-26.e1.

97. Ye LC, Liu TS, Ren L, et al. Randomized controlled trial of cetuximab plus chemotherapy for patients with KRAS wild-type unresectable colorectal liver-limited metastases. J Clin Oncol 2013;31:1931-8.

98. Siu LL, Shapiro JD, Jonker DJ, et al. Phase III randomized, placebo-controlled study of cetuximab plus brivanib alaninate versus cetuximab plus placebo in patients with metastatic, chemotherapy-refractory, wildtype K-RAS colorectal carcinoma: the NCIC Clinical Trials Group and AGITG CO.20 Trial. J Clin Oncol 2013;31:2477-84.

99. Brodowicz T, Ciuleanu TE, Radosavljevic D, et al. FOLFOX4 plus cetuximab administered weekly or every second week in the first-line treatment of patients with KRAS wild-type metastatic colorectal cancer: a randomized phase II CECOG study. Ann Oncol 2013;24:1769-77.

100.Hong YS, Kim HJ, Park SJ, et al. Second-line cetuximab/ irinotecan versus oxaliplatin/fluoropyrimidines for metastatic colorectal cancer with wild-type KRAS. Cancer Sci 2013;104:473-80.

101. Assenat E, Desseigne F, Thezenas S, et al. Cetuximab plus FOLFIRINOX (ERBIRINOX) as first-line treatment for unresectable metastatic colorectal cancer: a phase II trial. Oncologist 2011;16:1557-64.

102.Kullmann F, Hartmann A, Stohr R, et al. KRAS mutation in metastatic pancreatic ductal adenocarcinoma: results of a multicenter phase II study evaluating efficacy of cetuximab plus gemcitabine/oxaliplatin (GEMOXCET) in first-line therapy. Oncology 2011;81:3-8.

103. Lim R, Sun Y, Im SA, et al. Cetuximab plus irinotecan in pretreated metastatic colorectal cancer patients: the ELSIE study. World J Gastroenterol 2011;17:1879-88.

104. Van Cutsem E, Kohne CH, Lang I, et al. Cetuximab plus irinotecan, fluorouracil, and leucovorin as first-line treatment for metastatic colorectal cancer: updated analysis of overall survival according to tumor KRAS and BRAF mutation status. J Clin Oncol 2011;29:2011-9.

105. Moosmann N, von Weikersthal LF, Vehling-Kaiser U, et al. Cetuximab plus capecitabine and irinotecan compared with cetuximab plus capecitabine and oxaliplatin as firstline treatment for patients with metastatic colorectal cancer: AIO KRK-0104--a randomized trial of the German AIO CRC study group. J Clin Oncol 2011;29:1050-8.

106. Wong NS, Fernando NH, Nixon AB, et al. A phase II study of capecitabine, oxaliplatin, bevacizumab and cetuximab in the treatment of metastatic colorectal cancer. Anticancer Res 2011;31:255-61.
107. Shitara K, Yokota T, Takahari D, et al. Phase II study of combination chemotherapy with irinotecan and cetuximab for pretreated metastatic colorectal cancer harboring wildtype KRAS. Invest New Drugs 2011;29:688-93.

108. Saridaki Z, Androulakis N, Vardakis N, et al. A triplet combination with irinotecan (CPT-11), oxaliplatin (LOHP), continuous infusion 5-fluorouracil and leucovorin (FOLFOXIRI) plus cetuximab as first-line treatment in KRAS wt, metastatic colorectal cancer: a pilot phase II trial. Br J Cancer 2012;107:1932-7.

109. Shitara K, Yuki S, Yoshida M, et al. Phase II study of combination chemotherapy with biweekly cetuximab and irinotecan for wild-type KRAS metastatic colorectal cancer refractory to irinotecan, oxaliplatin, and fluoropyrimidines. Invest New Drugs 2012;30:787-93.

110. Tveit KM, Guren T, Glimelius B, et al. Phase III trial of cetuximab with continuous or intermittent fluorouracil, leucovorin, and oxaliplatin (Nordic FLOX) versus FLOX alone in first-line treatment of metastatic colorectal cancer: the NORDIC-VII study. J Clin Oncol 2012;30:1755-62.

111.Zhu J, Lian P, Liu F, et al. Phase II trial of first-line chemoradiotherapy with intensity-modulated radiation therapy followed by chemotherapy for synchronous unresectable distant metastases rectal adenocarcinoma. Radiat Oncol 2013;8:10.

112. Mizushima T, Ikeda M, Kato T, et al. Postoperative XELOX therapy for patients with curatively resected high-risk stage II and stage III rectal cancer without preoperative chemoradiation: a prospective, multicenter, open-label, single-arm phase II study. BMC Cancer 2019;19:929.

113. Yoshimatsu K, Ishibashi K, Koda K, et al. A Japanese multicenter phase II study of adjuvant chemotherapy with mFOLFOX6/CAPOX for stage III colon cancer treatment after D2/D3 lymphadenectomy. Surg Today 2019;49:498-506.

114. Nishimura J, Hasegawa J, Kato T, et al. Phase II trial of capecitabine plus oxaliplatin (CAPOX) as perioperative therapy for locally advanced rectal cancer. Cancer Chemother Pharmacol 2018;82:707-16.

115. Larsen FO, Markussen A, Jensen BV, et al. Capecitabine and oxaliplatin before, during, and after radiotherapy for high-risk rectal cancer. Clin Colorectal Cancer 2017;16:e7-14.

116. Danno K, Hata T, Tamai K, et al. Interim analysis of a phase II trial evaluating the safety and efficacy of capecitabine plus oxaliplatin (XELOX) as adjuvant therapy in Japanese patients with operated stage III colon cancer. 
Cancer Chemother Pharmacol 2017;80:777-85.

117.Azria D, Doyen J, Jarlier M, et al. Late toxicities and clinical outcome at 5 years of the ACCORD 12/0405-PRODIGE 02 trial comparing two neoadjuvant chemoradiotherapy regimens for intermediate-risk rectal cancer. Ann Oncol 2017;28:2436-42.

118. Liu F, Yang L, Wu Y, et al. CapOX as neoadjuvant chemotherapy for locally advanced operable colon cancer patients: a prospective single-arm phase II trial. Chin J Cancer Res 2016;28:589-97.

119. Pilancı KN, Saglam S, Okyar A, et al. Chronomodulated oxaliplatin plus Capecitabine (XELOX) as a first line chemotherapy in metastatic colorectal cancer: a Phase II Brunch regimen study. Cancer Chemother Pharmacol 2016;78:143-50.

120.Feng YR, Zhu Y, Liu LY, et al. Interim analysis of postoperative chemoradiotherapy with capecitabine and oxaliplatin versus capecitabine alone for pathological stage II and III rectal cancer: a randomized multicenter phase III trial. Oncotarget 2016;7:25576-84.

121. Sclafani F, Chau I, Cunningham D, et al. Sequence variation in mature microRNA-608 and benefit from neo-adjuvant treatment in locally advanced rectal cancer patients. Carcinogenesis 2016;37:852-7.

122. Kim JH, Zang DY, Chung IJ, et al. A muti-center, randomized phase II study of oxaliplatin and S-1 versus capecitabine and oxaliplatin in patients with metastatic colorectal cancer. J Cancer 2015;6:1041-8.

123. Wong SJ, Moughan J, Meropol NJ, et al. Efficacy endpoints of radiation therapy group protocol 0247: a randomized, phase 2 study of neoadjuvant radiation therapy plus concurrent capecitabine and irinotecan or capecitabine and oxaliplatin for patients with locally advanced rectal cancer. Int J Radiat Oncol Biol Phys 2015;91:116-23.

124. Kim ST, Hong YS, Lim HY, et al. S-1 plus oxaliplatin versus capecitabine plus oxaliplatin for the first-line treatment of patients with metastatic colorectal cancer: updated results from a phase 3 trial. BMC Cancer 2014;14:883.

125.Gérard JP, Azria D, Gourgou-Bourgade S, et al. Clinical outcome of the ACCORD 12/0405 PRODIGE 2 randomized trial in rectal cancer. J Clin Oncol 2012;30:4558-65.

126. Salazar R, Navarro M, Losa F, et al. Phase II study of preoperative radiotherapy and concomitant weekly intravenous oxaliplatin combined with oral capecitabine for stages II-III rectal cancer. Clin Transl Oncol 2012;14:592-8.
127. Arbea L, Martinez-Monge R, Diaz-Gonzalez JA, et al. Four-week neoadjuvant intensity-modulated radiation therapy with concurrent capecitabine and oxaliplatin in locally advanced rectal cancer patients: a validation phase II trial. Int J Radiat Oncol Biol Phys 2012;83:587-93.

128.Schou JV, Larsen FO, Rasch L, et al. Induction chemotherapy with capecitabine and oxaliplatin followed by chemoradiotherapy before total mesorectal excision in patients with locally advanced rectal cancer. Ann Oncol 2012;23:2627-33.

129. Ducreux M, Bennouna J, Hebbar M, et al. Capecitabine plus oxaliplatin (XELOX) versus 5-fluorouracil/leucovorin plus oxaliplatin (FOLFOX-6) as first-line treatment for metastatic colorectal cancer. Int J Cancer 2011;128:682-90.

130.Haller DG, Tabernero J, Maroun J, et al. Capecitabine plus oxaliplatin compared with fluorouracil and folinic acid as adjuvant therapy for stage III colon cancer. J Clin Oncol 2011;29:1465-71.

131. Waddell T, Gollins S, Soe W, et al. Phase II study of shortcourse capecitabine plus oxaliplatin (XELOX) followed by maintenance capecitabine in advanced colorectal cancer: XelQuali study. Cancer Chemother Pharmacol 2011;67:1111-7.

132. Baraniskin A, Munding J, Schulmann K, et al. Prognostic value of reduced SMAD4 expression in patients with metastatic colorectal cancer under oxaliplatin-containing chemotherapy: a translational study of the AIO colorectal study group. Clin Colorectal Cancer 2011;10:24-9.

133. Cassidy J, Clarke S, Diaz-Rubio E, et al. XELOX vs FOLFOX-4 as first-line therapy for metastatic colorectal cancer: NO16966 updated results. Br J Cancer 2011;105:58-64.

134.Li YH, Luo HY, Wang FH, et al. Phase II study of capecitabine plus oxaliplatin (XELOX) as first-line treatment and followed by maintenance of capecitabine in patients with metastatic colorectal cancer. J Cancer Res Clin Oncol 2010;136:503-10.

135. Qvortrup C, Jensen BV, Fokstuen T, et al. A randomized study comparing short-time infusion of oxaliplatin in combination with capecitabine $\operatorname{XELOX}(30)$ and chronomodulated $\mathrm{XELOX}(30)$ as first-line therapy in patients with advanced colorectal cancer. ANN ONCOL 2010;21:87-91.

136. Houts AC, Ogale S, Zafar Y, et al. Progression-free survival in patients receiving chemotherapy alone $(\mathrm{C})$ or chemotherapy with bevacizumab (CB) for first-line treatment of KRAS mutant metastatic colorectal cancer in community oncology settings. J Gastrointest Cancer 
2019;50:16-22.

137.Degirmencioglu S, Tanriverdi O, Menekse S, et al. A retrospective analysis on first-line bevacizumab, cetuximab, and panitimumab-containing regimens in patients with RAS-wild metastatic colorectal cancer: A Collaborative Study by Turkish Oncology Group (TOG). J BUON 2019;24:136-42.

138. Khakoo S, Chau I, Pedley I, et al. ACORN: Observational Study of Bevacizumab in Combination With First-Line Chemotherapy for Treatment of Metastatic Colorectal Cancer in the UK. Clin Colorectal Cancer 2019;18:280-91.e5.

139. Ogata T, Satake H, Ogata M, et al. Safety and effectiveness of FOLFOXIRI plus molecular target drug therapy for metastatic colorectal cancer: a multicenter retrospective study. Oncotarget 2019;10:1070-84.

140. Ottaiano A, Capozzi M, Tafuto S, et al. Folfiri-aflibercept vs. folfiri-bevacizumab as second line treatment of RAS mutated metastatic colorectal cancer in real practice. Front Oncol 2019;9:766.

141.Devaux M, Gerard L, Richard C, et al. Retrospective evaluation of FOLFIRI3 alone or in combination with bevacizumab or aflibercept in metastatic colorectal cancer. World J Clin Oncol 2019;10:75-85.

142. Turpin A, Paget-Bailly S, Ploquin A, et al. Clinical relevance of alternative endpoints in colorectal cancer first-line therapy with bevacizumab: a retrospective study. Clin Colorectal Cancer 2018;17:e99-107.

143. Matsusaka S, Cao S, Hanna DL, et al. CXCR4 polymorphism predicts progression-free survival in metastatic colorectal cancer patients treated with first-line bevacizumab-based chemotherapy. Pharmacogenomics J 2017;17:543-50.

144.Hasegawa H, Taniguchi H, Mitani S, et al. Efficacy of second-line bevacizumab-containing chemotherapy for patients with metastatic colorectal cancer following firstline treatment with an anti-epidermal growth factor receptor antibody. Oncology 2017;92:205-12.

145.Sun DC, Shi Y, Wang YR, et al. KRAS mutation and primary tumor location do not affect efficacy of bevacizumab-containing chemotherapy in stagae IV colorectal cancer patients. Sci Rep 2017;7:14368.

146. Bennouna J, Phelip JM, André T, et al. Observational cohort study of patients with metastatic colorectal cancer initiating chemotherapy in combination with bevacizumab (CONCERT). Clin Colorectal Cancer 2017;16:129-40.e4.

147. Chapman SJ, McKavanagh D, Burge ME, et al. Effectiveness of bevacizumab and cetuximab in metastatic colorectal cancer across selected public hospitals in Queensland. Asia Pac J Clin Oncol 2017;13:e253-61.

148. Bai L, Wang F, Li ZZ, et al. Chemotherapy plus bevacizumab versus chemotherapy plus cetuximab as first-line treatment for patients with metastatic colorectal cancer: Results of a registry-based cohort analysis. Medicine (Baltimore) 2016;95:e4531.

149. Dionísio de Sousa IJ, Ferreira J, Rodrigues J, et al. Association between bevacizumab-related hypertension and response to treatment in patients with metastatic colorectal cancer. ESMO Open 2016;1:e000045.

150. Kotaka M, Ikeda F, Tsujie M, et al. Observational cohort study focused on treatment continuity of patients administered XELOX plus bevacizumab for previously untreated metastatic colorectal cancer. Onco Targets Ther 2016;9:4113-20.

151. Wong HL, Lee B, Field K, et al. Impact of primary tumor site on bevacizumab efficacy in metastatic colorectal cancer. Clin Colorectal Cancer 2016;15:e9-15.

152. Cabart M, Frénel JS, Campion L, et al. Bevacizumab efficacy is influenced by primary tumor resection in first-line treatment of metastatic colorectal cancer in a retrospective multicenter study. Clin Colorectal Cancer 2016;15:e165-74.

153. Kocakova I, Melichar B, Kocak I, et al. Bevacizumab with FOLFIRI or XELIRI in the First-line Therapy of Metastatic Colorectal Carcinoma: Results from Czech Observational Registry. Anticancer Res 2015;35:3455-61.

154.Hammerman A, Greenberg-Dotan S, Battat E, et al. The 'real-life' impact of adding bevacizumab to firstline therapy in metastatic colorectal cancer patients: a large Israeli retrospective cohort study. Acta Oncol 2015;54:164-70.

155. Stein A, Petersen V, Schulze M, et al. Bevacizumab plus chemotherapy as first-line treatment for patients with metastatic colorectal cancer: results from a large German community-based observational cohort study. Acta Oncol 2015;54:171-8.

156. Bai L, Zhang DS, Wu WJ, et al. Clinical outcomes of Chinese patients with metastatic colorectal cancer receiving first-line bevacizumab-containing treatment. Med Oncol 2015;32:469.

157. Bencsikova B, Bortlicek Z, Halamkova J, et al. Efficacy of bevacizumab and chemotherapy in the first-line treatment of metastatic colorectal cancer: broadening KRAS-focused clinical view. BMC Gastroenterol 2015;15:37.

158. Tahover E, Hubert A, Temper M, et al. An observational cohort study of bevacizumab and chemotherapy in 
metastatic colorectal cancer patients: safety and efficacy with analysis by age group. Target Oncol 2015;10:55-63.

159.Kubáčková K, Bortlíček Z, Pikus T, et al. Bevacizumab with chemotherapy in patients with KRAS wild-type metastatic colorectal cancer: Czech registry data. Future Oncol 2015;11:225-32.

160. Cheng Y, Song W. Efficacy of FOLFOXIRI versus XELOXIRI plus bevacizumab in the treatment of metastatic colorectal cancer. Int J Clin Exp Med 2015;8:18713-20.

161. Ohhara Y, Suenaga M, Matsusaka S, et al. Comparison between three oxaliplatin-based regimens with bevacizumab in patients with metastatic colorectal cancer. Onco Targets Ther 2015;8:529-37.

162. Yang YH, Lin JK, Chen WS, et al. Comparison of cetuximab to bevacizumab as the first-line biochemotherapy for patients with metastatic colorectal cancer: superior progression-free survival is restricted to patients with measurable tumors and objective tumor response--a retrospective study. J Cancer Res Clin Oncol 2014;140:1927-36.

163. Fourrier-Réglat A, Smith D, Rouyer M, et al. Survival outcomes of bevacizumab in first-line metastatic colorectal cancer in a real-life setting: results of the ETNA cohort. Target Oncol 2014;9:311-9.

164. Hofheinz R, Petersen V, Kindler M, et al. Bevacizumab in first-line treatment of elderly patients with metastatic colorectal cancer: German community-based observational cohort study results. BMC Cancer 2014;14:761.

165. Suenaga M, Mizunuma N, Matsusaka S, et al. Retrospective analysis on the efficacy of bevacizumab with FOLFOX as a first-line treatment in Japanese patients with metastatic colorectal cancer. Asia Pac J Clin Oncol 2014;10:322-9.

166. Uchima Y, Nishii T, Iseki Y, et al. Retrospective analysis of capecitabine and oxaliplatin (XELOX) plus bevacizumab as a first-line treatment for Japanese patients with metastatic colorectal cancer. Mol Clin Oncol 2014;2:134-8.

167. Yin C, Jiang C, Liao F, et al. Initial LDH level can predict the survival benefit from bevacizumab in the first-line setting in Chinese patients with metastatic colorectal cancer. Onco Targets Ther 2014;7:1415-22.

168. Hurwitz HI, Bekaii-Saab TS, Bendell JC, et al. Safety and effectiveness of bevacizumab treatment for metastatic colorectal cancer: final results from the Avastin((R)) Registry - Investigation of Effectiveness and Safety (ARIES) observational cohort study. Clin Oncol (R Coll Radiol) 2014;26:323-32.
169. Kiss I, Bortlicek Z, Melichar B, et al. Efficacy and toxicity of bevacizumab on combination with chemotherapy in different lines of treatment for metastatic colorectal carcinoma. Anticancer Res 2014;34:949-54.

170. Turan N, Benekli M, Dane F, et al. Adjuvant systemic chemotherapy with or without bevacizumab in patients with resected pulmonary metastases from colorectal cancer. Thorac Cancer 2014;5:398-404.

171. Moscetti L, Nelli F, Fabbri MA, et al. Maintenance single-agent bevacizumab or observation after firstline chemotherapy in patients with metastatic colorectal cancer: a multicenter retrospective study. Invest New Drugs 2013;31:1035-43.

172. Cvetanovic A, Vrbic S, Filipovic S, et al. Safety and efficacy of addition of bevacizumab to oxaliplatin-based preoperative chemotherapy in colorectal cancer with liver metastasis- a single institution experience. J BUON 2013;18:641-6.

173. Wu Q, Shi Y, Chen L, et al. Effect and safety of bevacizumab-containing chemotherapy treatment in Chinese patients with metastatic colorectal cancer. Onco Targets Ther 2013;6:485-90.

174. Meyerhardt JA, Li L, Sanoff HK, et al. Effectiveness of bevacizumab with first-line combination chemotherapy for Medicare patients with stage IV colorectal cancer. J Clin Oncol 2012;30:608-15.

175. Ghiringhelli F, Vincent J, Guiu B, et al. Bevacizumab plus FOLFIRI-3 in chemotherapy-refractory patients with metastatic colorectal cancer in the era of biotherapies. Invest New Drugs 2012;30:758-64.

176. Yildiz R, Buyukberber S, Uner A, et al. Bevacizumab plus irinotecan-based therapy in metastatic colorectal cancer patients previously treated with oxaliplatin-based regimens. Cancer Invest 2010;28:33-7.

177.Dranitsaris G, Edwards S, Edwards J, et al. Bevacizumab in combination with FOLFIRI chemotherapy in patients with metastatic colorectal cancer: an assessment of safety and efficacy in the province of Newfoundland and Labrador. Curr Oncol 2010;17:12-6.

178. Rouyer M, Francois E, Cunha AS, et al. Effectiveness of cetuximab as first-line therapy for patients with wildtype KRAS and unresectable metastatic colorectal cancer in real-life practice: results of the EREBUS cohort. Clin Colorectal Cancer 2018;17:129-39.

179. Wu X, Deng BB, Bai CM, et al. Efficacy and prognostic factors of cetuximab therapy in treating KRAS or all RAS wild-type metastatic colorectal cancer. Zhongguo Yi Xue Ke Xue Yuan Xue Bao 2018;40:660-6. 
180.Jerzak KJ, Berry S, Ko YJ, et al. Cetuximab plus irinotecan versus panitumumab in patients with refractory metastatic colorectal cancer in Ontario, Canada. Int J Cancer 2017;140:2162-7.

181.Kim D, Kim SY, Lee JS, et al. Primary tumor location predicts poor clinical outcome with cetuximab in RAS wild-type metastatic colorectal cancer. BMC Gastroenterol 2017;17:121.

182. Ozaslan E, Topaloglu US, Inanc M, et al. Efficacy and safety of cetuximab plus FOLFOX in second-line and third-line therapy in metastatic colorectal cancer. J BUON 2017;22:863-8.

183. Derangère V, Fumet JD, Boidot R, et al. Does bevacizumab impact anti-EGFR therapy efficacy in metastatic colorectal cancer? Oncotarget 2016;7:9309-21.

184. Pinto C, Di Fabio F, Rosati G, et al. Observational study on quality of life, safety, and effectiveness of firstline cetuximab plus chemotherapy in KRAS wild-type metastatic colorectal cancer patients: the ObservEr study. Cancer Med 2016;5:3272-81.

185. Uemura M, Kim HM, Hata T, et al. First-line cetuximabbased chemotherapies for patients with advanced or metastatic KRAS wild-type colorectal cancer. Mol Clin Oncol 2016;5:375-9.

186. Yamaguchi T, Iwasa S, Nagashima K, et al. Comparison of panitumumab plus irinotecan and cetuximab plus irinotecan for KRAS wild-type metastatic colorectal cancer. Anticancer Res 2016;36:3531-6.

187.Feng Q, Wei Y, Ren L, et al. Efficacy of continued cetuximab for unresectable metastatic colorectal cancer after disease progression during first-line cetuximab-based chemotherapy: a retrospective cohort study. Oncotarget 2016;7:11380-96.

188. Sato Y, Matsusaka S, Suenaga M, et al. Cetuximab could be more effective without prior bevacizumab treatment in metastatic colorectal cancer patients. Onco Targets Ther 2015;8:3329-36.

189. Wang F, Bai L, Liu TS, et al. Right-sided colon cancer and left-sided colorectal cancers respond differently to cetuximab. Chin J Cancer 2015;34:384-93.

190. Giampieri R, Mandolesi A, Abouelkhair KM, et al. Prospective study of a molecular selection profile for RAS wild type colorectal cancer patients receiving irinotecancetuximab. J Transl Med 2015;13:140.

191.Jehn CF, Boning L, Kroning H, et al. Influence of comorbidity, age and performance status on treatment efficacy and safety of cetuximab plus irinotecan in irinotecan-refractory elderly patients with metastatic colorectal cancer. Eur J Cancer 2014;50:1269-75.

192. Kennecke H, Chen L, Blanke CD, et al. Panitumumab monotherapy compared with cetuximab and irinotecan combination therapy in patients with previously treated KRAS wild-type metastatic colorectal cancer. Curr Oncol 2013;20:326-32.

193. Chen MC, Chiang FF, Wang HM. Cetuximab plus chemotherapy as first-line treatment for metastatic colorectal cancer: effect of KRAS mutation on treatment efficacy in Taiwanese patients. Neoplasma 2013;60:561-7.

194. Santos-Ramos B, Fernandez-Fernandez R, Marin-Gil R, et al. Use of monoclonal antibodies for metastatic colorectal cancer in the Andalusian public health system. Int J Clin Pharm 2013;35:550-3.

195.Jehn CF, Boning L, Kroning H, et al. Cetuximab-based therapy in elderly comorbid patients with metastatic colorectal cancer. Br J Cancer 2012;106:274-8.

196. Bouchahda M, Macarulla T, Liedo G, et al. Feasibility of cetuximab given with a simplified schedule every 2 weeks in advanced colorectal cancer: a multicenter, retrospective analysis. Med Oncol 2011;28 Suppl 1:S253-8.

197.Xu JL, Tang CW, Feng WM, et al. Prolonged capecitabine chemotherapy following capecitabine and oxaliplatin (CAPOX) regimen chemotherapy failed to improve survival of stage III colorectal cancer after radical resection. Med Sci Monit 2019;25:4831-6.

198. Loree JM, Sha A, Soleimani M, et al. Survival impact of CAPOX versus FOLFOX in the adjuvant treatment of stage III colon cancer. Clin Colorectal Cancer 2018;17:156-63.

199. Sha A, Abadi S, Gill S. Utilization of capecitabine plus oxaliplatin and 5-fluorouracil/folinic acid plus oxaliplatin in the adjuvant treatment of stage IIB and stage III colon cancer: a multi-centre, retrospective, chart review study. J Oncol Pharm Pract 2018;24:501-6.

200.van Erning FN, Janssen-Heijnen ML, Creemers GJ, et al. Recurrence-free and overall survival among elderly stage III colon cancer patients treated with CAPOX or capecitabine monotherapy. Int J Cancer 2017;140:224-33.

201. Nakanishi M, Kuriu Y, Murayama Y, et al. A study on the tolerability of capecitabine plus oxaliplatin as adjuvant chemotherapy. Anticancer Res 2016;36:1851-4.

202. Nielsen K, Scheffer HJ, Volders JH, et al. Radiofrequency ablation to improve survival after conversion chemotherapy for colorectal liver metastases. World J Surg 2016;40:1951-8.

203. Spada F, Antonuzzo L, Marconcini R, et al. Oxaliplatinbased chemotherapy in advanced neuroendocrine tumors: 
clinical outcomes and preliminary correlation with biological factors. Neuroendocrinology 2016;103:806-14.

204. Osawa H, Handa N, Minakata K. Efficacy and safety of capecitabine and oxaliplatin (CapOX) as an adjuvant therapy in Japanese for stage II/III colon cancer in a group at high risk of recurrence in retrospective study. Oncol Res 2014;22:325-31.

205.Loree JM, Mulder KE, Ghosh S, et al. CAPOX associated with toxicities of higher grade but improved disease-free survival when compared with FOLFOX in the adjuvant treatment of stage III colon cancer. Clin Colorectal Cancer 2014;13:172-7.

206. Chiu J, Tang V, Leung R, et al. Efficacy and tolerability of adjuvant oral capecitabine plus intravenous oxaliplatin (XELOX) in Asian patients with colorectal cancer: 4-year analysis. Asian Pac J Cancer Prev 2014;14:6585-90.

207.Loree JM, Mulder KE, Ghosh S, et al. Retrospective comparison of CAPOX and FOLFOX dose intensity, toxicity, and clinical outcomes in the treatment of metastatic colon cancer. J Gastrointest Cancer 2014;45:154-60.

208. Boisen MK, Dehlendorff C, Linnemann D, et al. Tissue microRNAs as predictors of outcome in patients with metastatic colorectal cancer treated with first line Capecitabine and Oxaliplatin with or without Bevacizumab. PLoS One 2014;9:e109430.

209. Qiu MZ, Wei XL, Zhang DS, et al. Efficacy and safety of capecitabine as maintenance treatment after firstline chemotherapy using oxaliplatin and capecitabine in advanced gastric adenocarcinoma patients: a prospective observation. Tumour Biol 2014;35:4369-75.

210. Fukuchi M, Ishibashi K, Tajima Y, et al. Oxaliplatin-

Cite this article as: Zhang $\mathrm{X}, \mathrm{Fu} \mathrm{S}$, Meng R, Ren Y, Shang Y, Tian L. Is there an efficacy-effectiveness gap between randomized controlled trials and real-world studies in colorectal cancer: a systematic review and meta-analysis. Transl Cancer Res 2020;9(11):6963-6987. doi: 10.21037/tcr-20-2303 based chemotherapy in patients aged 75 years or older with metastatic colorectal cancer. Anticancer Res 2013;33:4627-30.

211. Constantinidou A, Cunningham D, Shurmahi F, et al. Perioperative chemotherapy with or without bevacizumab in patients with metastatic colorectal cancer undergoing liver resection. Clin Colorectal Cancer 2013;12:15-22.

212. Hansen TF, Sørensen FB, Lindebjerg J, et al. The predictive value of microRNA-126 in relation to first line treatment with capecitabine and oxaliplatin in patients with metastatic colorectal cancer. BMC Cancer 2012;12:83.

213. Satram-Hoang S, Lee L, Yu S, et al. Comparative effectiveness of chemotherapy in elderly patients with metastatic colorectal cancer. J Gastrointest Cancer 2013;44:79-88.

214. Karacetin D, Yalcin B, Okten B, et al. Capecitabine and oxaliplatin (XELOX) as first-line treatment for patients with metastatic colorectal cancer. J BUON 2009;14:605-8.

215. Creel AH, Losina E, Mandl LA, et al. An assessment of willingness to participate in a randomized trial of arthroscopic knee surgery in patients with osteoarthritis. Contemp Clin Trials 2005;26:169-78.

216. Del Prete S, Cennamo G, Leo L, et al. Adherence and safety of regorafenib for patients with metastatic colorectal cancer: observational real-life study. Future Oncol 2017;13:415-23.

217. Featherston EL, Dihigo S, Gilder RE. Improving adherence to atypical antipsychotic agent screening guidelines in pediatric patients: a quality improvement project within an integrated community mental health setting. J Am Psychiatr Nurses Assoc 2018;24:352-9. 